\title{
Hydrogen Induced Structure and Property Changes in $\mathrm{Eu}_{3} \mathrm{Si}_{4}$
}

Gustav Ek ${ }^{\mathrm{a}}$, Reji Nedumkandathil ${ }^{\mathrm{b}}$, Robert Johansson ${ }^{\mathrm{c}}$, Jorge Montero ${ }^{\mathrm{d}}$, Claudia Zlotea ${ }^{\mathrm{d}}$, Mikael S. Andersson ${ }^{\mathrm{e}, * *}$, Per Nordblad ${ }^{\mathrm{e}}$, Chiu Tang ${ }^{\mathrm{f}}$, Martin Sahlberg ${ }^{\mathrm{a}}$, Ulrich Häussermann ${ }^{\mathrm{b}, *}$

${ }^{a}$ Department of Chemistry - Angström laboratory, Uppsala University, Sweden

${ }^{b}$ Department of Materials and Environmental Chemistry, Stockholm University, Sweden

${ }^{c}$ Department of Physics and Astronomy, Uppsala University, Sweden

${ }^{d}$ Université Paris Est, Institut de Chimie et des Matériaux Paris-Est, CNRS, France

${ }^{e}$ Department of Engineering Sciences, Uppsala University, Sweden

${ }^{f}$ Diamond Light Source, Harwell Science and Innovation Campus, UK

“Ulrich.Haussermann@mmk.su.se

** Present address: Department of Chemistry and Chemical Engineering, Chalmers University of Technology, Sweden 


\begin{abstract}
Hydrides $\mathrm{Eu}_{3} \mathrm{Si}_{4} \mathrm{H}_{2+x}$ were obtained by exposing the Zintl phase $\mathrm{Eu}_{3} \mathrm{Si}_{4}$ to a hydrogen atmosphere at a pressure of 30 bar and temperatures from 25 to $300{ }^{\circ} \mathrm{C}$. Structural analysis using powder X-ray diffraction (PXRD) data suggested that hydrogenations in a temperature range $25-200{ }^{\circ} \mathrm{C}$ afford a uniform hydride phase with an orthorhombic structure (Immm, $a \approx$ $4.40 \AA, b \approx 3.97 \AA, c \approx 19.8 \AA$ ), whereas at $300^{\circ} \mathrm{C}$ mixtures of two orthorhombic phases with $c \approx 19.86$ and $\approx 19.58 \AA$ were obtained. The assignment of a composition $\mathrm{Eu}_{3} \mathrm{Si}_{4} \mathrm{H}_{2+\mathrm{x}}$ is based on first principles DFT calculations, which indicated a distinct crystallographic site for $\mathrm{H}$ in the $\mathrm{Eu}_{3} \mathrm{Si}_{4}$ structure. In this position, $\mathrm{H}$ atoms are coordinated in a tetrahedral fashion by $\mathrm{Eu}$ atoms. The resulting hydride $\mathrm{Eu}_{3} \mathrm{Si}_{4} \mathrm{H}_{2}$ is stable by $-0.46 \mathrm{eV} / \mathrm{H}$ atom with respect to $\mathrm{Eu}_{3} \mathrm{Si}_{4}$ and gaseous $\mathrm{H}_{2}$. Deviations between the lattice parameters of the DFT optimized $\mathrm{Eu}_{3} \mathrm{Si}_{4} \mathrm{H}_{2}$ structure and the ones extracted from PXRD patterns pointed to the presence of additional $\mathrm{H}$ in interstitials also involving Si atoms. Subsequent DFT modeling of compositions $\mathrm{Eu}_{3} \mathrm{Si}_{4} \mathrm{H}_{3}$ and $\mathrm{Eu}_{3} \mathrm{Si}_{4} \mathrm{H}_{4}$ showed considerably better agreement to the experimental unit cell volumes. It was then concluded that the hydrides of $\mathrm{Eu}_{3} \mathrm{Si}_{4}$ have a composition $\mathrm{Eu}_{3} \mathrm{Si}_{4} \mathrm{H}_{2+x}(x<2)$ and are disordered with respect to $\mathrm{H}$ in $\mathrm{Si}_{2} \mathrm{Eu}_{3}$ interstitials. $\mathrm{Eu}_{3} \mathrm{Si}_{4}$ is a ferromagnet with a $\mathrm{T}_{C}$ at about $120 \mathrm{~K}$. Ferromagnetism is effectively quenched in $\mathrm{Eu}_{3} \mathrm{Si}_{4} \mathrm{H}_{2+x}$. The effective magnetic moment for both materials is $7.5 \mu_{\mathrm{B}}$ which is typical for compounds containing $\mathrm{Eu}^{2+} 4 \mathrm{f}^{7}$ ions.
\end{abstract}

Keywords: Zintl phases, Zintl phase hydrides, rare earth metal silicides, magnetic properties 


\section{Introduction}

Zintl phases, which are composed of an active metal (i.e. alkali, alkaline earth, or rare earth) and a more electronegative p-block metal or semimetal, represent a large family of inorganic compounds [1-3]. As their characteristic feature, atoms of the electronegative component appear reduced and may form polyanionic structures to achieve an octet. Like many intermetallic compounds Zintl phases can react with hydrogen to form hydrides. However, the rather high ionicity of Zintl phases makes such hydrides peculiar. Hydrogen takes an ambivalent role and can be incorporated in two principal ways: either hydridic, where $\mathrm{H}$ is exclusively coordinated by active metals (interstitial hydrides), or as part of the polyanion where it acts as a covalently bonded ligand (polyanionic hydrides) [4,5]. Chemical structures and physical properties of Zintl phases can change profoundly upon $\mathrm{H}$ incorporation. This provides interesting prospects for fundamental inorganic chemistry and materials science.

Well investigated are the hydrogenation induced metal-semiconductor transitions for the systems MTrTt $-\mathrm{MTrTtH}(\mathrm{M}=$ alkaline earth; $\mathrm{Tr}=\mathrm{Al}, \mathrm{Ga}, \mathrm{In} ; \mathrm{Tt}=\mathrm{Si}, \mathrm{Ge}, \mathrm{Sn})$. Here charge imbalanced $\mathrm{AlB}_{2}$-type related Zintl phases form charge balanced semiconductor hydrides in which $\mathrm{H}$ is bonded to $\mathrm{Tr}$ and thus part of the polyanion [6,7]. Further, it has been shown that CrB-type related Zintl phases MTt can be hydrogenated to yield hydrides $\mathrm{MTtH}_{1+\mathrm{x}}$ with $\mathrm{x}$ $\sim 0.33, \sim 0.67$, and $\sim 0.87$ featuring novel ribbon- and chain-like polyanions $\left[\mathrm{Tt}_{3} \mathrm{H}\right]^{3-},\left[\mathrm{Tt}_{2} \mathrm{H}\right]^{2-}$, and $[\mathrm{TtH}]^{-}$in which $\mathrm{H}$ is covalently bonded to a $\mathrm{Tt}$ element $[8,9]$. The discovery of polyanions with $\mathrm{Tt}-\mathrm{H}$ bonds represented an important extension of Zintl phase hydrides. Another peculiar feature of $\mathrm{MTtH}_{1+\mathrm{x}}$ is the simultaneous presence of interstitial $\mathrm{H}$ which is exclusively coordinated by $\mathrm{M}$ and not bonded to $\mathrm{Tt}$. The $\mathrm{CrB}$ structure type is also adopted for most rare earth (RE) monogallides, REGa, which - considering RE as trivalent - are isoelectronic to MTt. In contrast with MTt, the REGa compounds display cooperative magnetism. Recent studies on $\mathrm{NdGa}$ and $\mathrm{GdGa}$ showed that, similar to MTt, also REGa transform into hydrides $\mathrm{REGaH}_{1+x}$ by incorporating $\mathrm{H}$ both interstitially (i.e. exclusively coordinated by RE atoms) and as part of a two-dimensional Ga-H polyanion. At the same time the magnetic interaction is changed from ferromagnetic to antiferromagnetic nature $[10,11,12]$.

In this paper we report on the hydrogenation behavior of $\mathrm{Eu}_{3} \mathrm{Si}_{4} . \mathrm{Eu}_{3} \mathrm{Si}_{4}$ was first described in 2004 [13]. Its body centered orthorhombic crystal structure (space group Immm, \#71) is depicted in Figure 1 [14]. Si atoms form hexagon rings, which in turn are condensed into onedimensional ribbons that run in the $b$ direction (Figure 1a). Following the Zintl concept, threebonded ( $3 b$ ) Si atoms (henceforth termed Si1) carry a formal charge of -1, and two-bonded (2b) ones (henceforth termed Si2) carry a charge of -2 . A polyanionic strand is composed of four $\mathrm{Si}$ atoms, $2 \mathrm{Si} 1$ and $2 \mathrm{Si} 2$ (there are two equivalent strands in the body centered unit cell). Thus, a strand $\left[\mathrm{Si}_{2} \mathrm{Si}_{2}\right.$ ] carries a formal charge of -6 , which is balanced by Eu cations, provided they are in $\mathrm{a}+2$ state. The divalent character of Eu was confirmed from magnetic measurements, which showed a magnetic moment in agreement with a $4 \mathrm{f}^{7}$ electron configuration when $\mathrm{Eu}_{3} \mathrm{Si}_{4}$ is in the paramagnetic state above $117 \mathrm{~K}$ [13]. Eu1 atoms are situated between Si hexagon rings. Eu2 atoms form arrays of edge condensed tetrahedra, which separate $\mathrm{Si}$ hexagon ribbons in the $c$ direction. Both $\mathrm{Eu}$ atoms together provide a 
trigonal prismatic coordination to $\mathrm{Si}$ atoms (Figure $1 \mathrm{~b}$ ). There is an apparent close relationship to the orthorhombic CrB structure (space group $\mathrm{Cmcm} \mathrm{\# 63),} \mathrm{which} \mathrm{is} \mathrm{adopted} \mathrm{by} \mathrm{the} \mathrm{REGa}$ compounds (Figure 1b). Their structure is built from slabs of trigonal prims formed by the RE atoms, which host $\mathrm{Ga}$ atoms that are arranged as zigzag chains. The $\mathrm{Eu}_{3} \mathrm{Si}_{4}$ structure can be considered as built up from slabs of $\mathrm{CrB}$ structure (with a thickness $b / 2$ ) with alternating [010] and [0-10] orientation. Condensing slabs at layers of common RE atoms will then connect zigzag chains into hexagon rings.

$\mathrm{Eu}_{3} \mathrm{Si}_{4}$ displays two magnetic transitions at 117 and $40 \mathrm{~K}$ [13]. The first one is attributed to a ferromagnetic ordering of the Eu2 atoms. This transition probably relates to the ferromagnetic transition in REGa compounds because RE atoms in REGa have the same structural arrangement as the $\mathrm{Eu} 2$ atoms in $\mathrm{Eu}_{3} \mathrm{Si}_{4}$. The Curie temperatures $\mathrm{T}_{\mathrm{C}}$ of $\mathrm{REGa}$ are in a range 15 - $190 \mathrm{~K}[15,16,17]$. The second transition in $\mathrm{Eu}_{3} \mathrm{Si}_{4}$ is caused by a ferromagnetic ordering of the Eu1 atoms, resulting in a net ferrimagnetic ground state. The ferromagnetic properties of $\mathrm{Eu}_{3} \mathrm{Si}_{4}$ must be a consequence of the coupling of magnetic moments arising from localized 4f electrons, which is mediated via conduction electrons. The validity of such a RKKY coupling mechanism, however, contradicts the description of $\mathrm{Eu}_{3} \mathrm{Si}_{4}$ as a charge balanced Zintl phase, because in this simple picture all valence electrons are localized as bonds and lone pairs within the Si polyanion, which would not leave any excess electrons for mediating ferromagnetic coupling. Again, this is similar to ferromagnetic REGa for which $\mathrm{H}$ incorporation triggers a transition from ferromagnetic to antiferrmomagnetic behavior $[10,11]$. In contrast with $\mathrm{Eu}_{3} \mathrm{Si}_{4}$, all $\mathrm{RE}$ atoms in REGa are crystallographically equivalent. 


\section{Methods}

\subsection{Synthesis}

All steps of synthesis and sample preparation were carried out in an Ar-filled glove box. Eu (99.9\%) and $\mathrm{Si}(99.999 \%)$ were purchased from $\mathrm{ABCR}$. $\mathrm{Eu}_{3} \mathrm{Si}_{4}$ was prepared by arc-melting stoichiometric mixtures of $\mathrm{Eu}$ and $\mathrm{Si}$. To ensure homogeneity, samples were re-melted five times and flipped between each melting. Slight changes in the stoichiometry or insufficient remelting led to the presence of EuSi and $\mathrm{EuSi}_{2}$ in the product. Most homogeneous samples $\mathrm{Eu}_{3} \mathrm{Si}_{4}$ were obtained when pre-reacting stoichiometric amounts of $\mathrm{Eu}$ and $\mathrm{Si}$ - enclosed in a Ta ampule - in an RF furnace for $2 \mathrm{~h}$ at about $1000{ }^{\circ} \mathrm{C}$ into a mixture of $\mathrm{Eu}_{3} \mathrm{Si}_{4}, \mathrm{EuSi}$, and $\mathrm{EuSi}_{2}$, and subsequently arc-melting this mixture. Buttons of $\mathrm{Eu}_{3} \mathrm{Si}_{4}$ from arc-melting were ground in an agate mortar and portions of 50-100 mg were pressed into pellets. The pellets were placed in an $\mathrm{Al}_{2} \mathrm{O}_{3}$ (corundum) crucible inside a custom-made stainless steel autoclave, which was subsequently pressurized to 30 bar with $\mathrm{H}_{2}$ gas. The autoclave was then placed inside a tube furnace and hydrogenations performed at room temperature, 100, 200, and 300 ${ }^{\circ} \mathrm{C}$ for $24 \mathrm{~h}$. The temperature inside the autoclave was monitored by a K-type thermocouple. Both $\mathrm{Eu}_{3} \mathrm{Si}_{4}$ and products obtained from its hydrogenation have a grey color and decompose when exposed to humid atmosphere. For purity check and phase analysis of samples, powder $\mathrm{X}$-Ray diffraction (PXRD) was employed.

\subsection{Pressure Composition Isotherm}

Hydrogen absorption properties were measured by Pressure-Composition-Isotherm (PCI) curves with a commercial volumetric device (SETARAM PCT PRO) equipped with calibrated and thermalized volumes and pressure gauges at $25{ }^{\circ} \mathrm{C}$. The sample holder corresponded to a stainless steel container closed with a metal seal and was inserted in a resistance furnace at 250 and $300{ }^{\circ} \mathrm{C}$. High purity hydrogen $(6 \mathrm{~N})$ was introduced step by step up to around 3 bar. Due to very slow kinetics, the time allowed for equilibrium was between 1500 and 2000 minutes per pressure point. It was compulsory to load the sample in an Arfilled glove box in order to avoid air-exposure since surface oxidation resulted in a dramatic decrease of kinetics, with sometimes no absorption.

\subsection{Structural Characterization of $\mathrm{Eu}_{3} \mathrm{Si}_{4}$ and hydrogenous $\mathrm{Eu}_{3} \mathrm{Si}_{4}$}

PXRD patterns were collected on a Panalytical X'Pert PRO diffractometer operated with $\mathrm{Cu}$ either $\mathrm{Cu} \mathrm{K} \alpha_{1}(\lambda=1.5406 \AA)$ radiation in $\theta-2 \theta$ diffraction geometry. Powder samples were mounted on a $\mathrm{Si}$ wafer zero-background holder and sealed between kapton tape to ensure an oxygen/moisture free atmosphere during data collection. Data were measured in a $2 \theta$ range 10 $-90^{\circ}$. High-energy X-ray diffraction experiments were carried out for $\mathrm{Eu}_{3} \mathrm{Si}_{4}$ and products from hydrogenations at 200 and $300{ }^{\circ} \mathrm{C}$ (Eu3Si4_H2_200C and Eu3Si4_H2_300C) at the beamline P02.1 at PETRAIII, DESY, which operates at a fixed energy of approximately 60 $\mathrm{keV}$. The wavelength was determined to be $0.20727(6) \AA$ by using a LaB 6 NIST standard. Powder samples were loaded in a glass capillary with $0.5 \mathrm{~mm}$ diameter. $2 \mathrm{D}$ diffraction images, each obtained through the accumulation of 20 frames with an exposure time of one second per frame, were collected with a Perkin Elmer amorphous silicon area detector 
(XRD1621) placed at $329 \mathrm{~mm}$ from the sample. The 2D diffraction images were then integrated into a linear scattering signal with the software Fit2D and averaged [18]. The Rietveld method [19] as implemented in the FULLPROF program (v. 2.05, July 2011) [20] was used for structure and phase analysis. Structure refinements of synchrotron data were based on the established structure model for $\mathrm{Eu}_{3} \mathrm{Si}_{4}$. A six-coefficient polynomial refinement was used for the background. Lattice parameters were fitted with the value from structure model. The peak shape was modeled by Thompson-Cox-Hastings pseudo-Voigt axial divergence asymmetry. Fits could be considerably improved when applying a preferred orientation correction to the intensities parallel to (101).

\subsection{In-situ diffraction}

In-situ Synchrotron PXRD experiments were performed at the I11 beamline at the Diamond light source, UK using a wavelength of $0.49404 \AA$ (as determined by a Si standard) and a wide-angle position sensitive detector based on Mythen-2 strip modules. The sample was loaded into a $0.7 \mathrm{~mm}$ quartz capillary that was mounted on a Norby type cell [21] and sealed using Epoxy. The cell was then mounted and leak checked with He gas before applying a pressure of 30 bar $\mathrm{H}_{2}$. Data was collected at $20 \mathrm{~s}$ per scan during a heat-cool temperature program (RT $-400{ }^{\circ} \mathrm{C}-\mathrm{RT}$ at $5{ }^{\circ} \mathrm{C} / \mathrm{min}$ ) using a hot-air blower. Consequently, the duration of the heating and cooling ramps were about $80 \mathrm{~min}$. In between the ramps a short period of dwelling ( $5 \mathrm{~min}$ ) was inserted. Data analysis was done by the Rietveld method implemented in the software TOPAS 6 academic [22] in sequential mode. Peak functions were described by the fundamental parameters approach and the background by a $6^{\text {th }}$ degree Chebychev polynomial. During sequential mode, unit cell parameters of three phases were refined (initial $\mathrm{Eu}_{3} \mathrm{Si}_{4}$, hydrogenous $\mathrm{Eu}_{3} \mathrm{Si}_{4}$, and the impurity phase $\mathrm{EuSi}_{2}$ ) along with scale factors and background parameters. All other parameters were kept fixed.

\subsection{Computations}

DFT calculations were performed using the Vienna ab initio Simulation Package (VASP) $[23,24]$ utilizing the projector augmented wave method (PAW) $[25,26]$ to treat the interactions between the electrons and the nuclei. The generalized gradient approximation (GGA) in the parametrization of the Perdew-Burke-Ernzerhof (PBE) [27] approach was employed to approximate the exchange and correlation. The plane wave basis set was terminated at a kinetic energy cutoff of $400 \mathrm{eV}$. The conjugate gradient algorithm was used to relax the atomic nuclei positions to a local minimum in the total energy landscape until the global break condition of maximum $10^{-3} \mathrm{eV} / \AA$ of force between the atoms was reached. A $25 \times 25 \times 7$ Monkhorst-Pack k-point mesh was used to sample the Brillouin zone[28] . Formation energies $\Delta \mathrm{E}$, referring to zero kelvin were calculated according to

$$
\Delta E=(1 / \mathrm{n})\left[E\left(\mathrm{Eu}_{3} \mathrm{Si}_{4} \mathrm{H}_{\mathrm{n}}\right)-E\left(\mathrm{Eu}_{3} \mathrm{Si}_{4}\right)-\mathrm{n} / 2 E\left(\mathrm{H}_{2}\right)\right]
$$

where $E$ denotes the total energy of the enclosed-in-parentheses system and $n=2,3,4$. For the $\mathrm{H}_{2}$ molecule, a box of $8 \times 8 \times 8 \AA^{3}$ dimensions was used with $\Gamma$-point sampling of the Brillouin zone. Structure relaxations were carried out for the compositions $\mathrm{Eu}_{3} \mathrm{Si}_{4} \mathrm{H}_{2}, \mathrm{Eu}_{3} \mathrm{Si}_{4} \mathrm{H}_{3}$ and 
$\mathrm{Eu}_{3} \mathrm{Si}_{4} \mathrm{H}_{4}$ using an orthorhombic starting cell with $\mathrm{Z}=2$. No symmetry restrictions were applied during relaxation and the Findsym program [30] was used to check for symmetry of atom arrangements after relaxations. Forces were converged to better than $10^{-3} \mathrm{eV} / \AA$. All materials were treated as non-magnetic and calculations were thus non spin-polarized.

\subsection{Magnetic Measurements}

Magnetization measurements were performed as a function of temperature using a Quantum Design MPMS SQUID magnetometer. M vs. T measurements were done both at low field (H $=4 \mathrm{kA} / \mathrm{m}$ ) in order to determine the transition temperature of the samples, as well as in high field $(\mathrm{H}=80 \mathrm{kA} / \mathrm{m})$ in order to do a Curie-Weiss fit and estimate the effective bohrmagneton number $\left(\mu_{\mathrm{eff}}\right)$ and Curie-Weiss temperature $\left(\Theta_{\mathrm{CW}}\right)$ of the samples. M vs. $\mathrm{H}$ measurements were performed at $6 \mathrm{~K}$ in the field range of $\pm 7200 \mathrm{kA} / \mathrm{m}$ using a Quantum Design PPMS VSM magnetometer to determine the saturation magnetization as well as study the field dependence of the sample. 


\section{Results and Discussion}

\subsection{Hydrogenation behavior of $\mathrm{Eu}_{3} \mathrm{Si}_{4}$}

Initially $\mathrm{Eu}_{3} \mathrm{Si}_{4}$ was exposed to a hydrogen atmosphere of 30 bar during $24 \mathrm{~h}$ at various temperatures in order to explore its hydrogen uptake behavior. Figure 2 shows selected PXRD patterns of reaction products. Pristine $\mathrm{Eu}_{3} \mathrm{Si}_{4}$ is remarkably susceptible to $\mathrm{H}$ uptake. As a matter of fact, kinetic barriers appear to be small because almost quantitative hydride formation is already observed at room temperature. At $100{ }^{\circ} \mathrm{C}$ and $200{ }^{\circ} \mathrm{C}$ a phase pure hydride was obtained. As will be explained later, we assign this hydride a composition $\mathrm{Eu}_{3} \mathrm{Si}_{4} \mathrm{H}_{2+x}$. After hydrogenation at $300{ }^{\circ} \mathrm{C}$ a changed PXRD pattern is observed. Notably, several reflections seem to be split, which may indicate the formation of another hydride. When hydrogenating at temperatures above $300{ }^{\circ} \mathrm{C}$, the crystallinity of products appears drastically reduced. Above $500{ }^{\circ} \mathrm{C}$ the product contained a substantial fraction $\mathrm{EuSi}_{2}$, indicating $\mathrm{H}$-induced oxidative decomposition. In this work we restrict ourselves to hydride phases obtained at low hydrogenation temperatures.

The diffraction patterns of $\mathrm{Eu}_{3} \mathrm{Si}_{4} \mathrm{H}_{2+x}$ from $100{ }^{\circ} \mathrm{C}$ and $200{ }^{\circ} \mathrm{C}$ hydrogenations (samples $\mathrm{Eu}_{3} \mathrm{Si}_{4} \_\mathrm{H}_{2} \_100 \mathrm{C}$ and $\mathrm{Eu}_{3} \mathrm{Si}_{4} \_\mathrm{H}_{2} \_200 \mathrm{C}$, respectively) could be readily indexed in a bodycentered orthorhombic cell with lattice parameters $a \approx 4.39 \AA, b \approx 3.97 \AA, c \approx 19.8 \AA$. As a matter of fact, these parameters resemble those of the starting material $\mathrm{Eu}_{3} \mathrm{Si}_{4}(a=4.6103(3)$ $\AA, b=3.9574(1) \AA, c=18.2239$ (4) $\AA$ ) [13] which suggests a close structural relationship between $\mathrm{Eu}_{3} \mathrm{Si}_{4} \mathrm{H}_{2+x}$ and $\mathrm{Eu}_{3} \mathrm{Si}_{4}$. In-house PXRD data was not suitable for Rietveld refinement. PXRD data collected at a synchrotron were of vastly superior quality. Synchrotron PXRD patterns of the starting material and of the hydrogenated samples at 200 ${ }^{\circ} \mathrm{C}$ and $300{ }^{\circ} \mathrm{C}$ are shown in Figure 3. The pattern of the $300{ }^{\circ} \mathrm{C}$ product (sample $\mathrm{Eu}_{3} \mathrm{Si}_{4} \_\mathrm{H}_{2} \_300 \mathrm{C}$ ) could be satisfactorily refined as a mixture of two orthorhombic phases. The first phase corresponds well to the hydride phase obtained in the $200{ }^{\circ} \mathrm{C}$ experiment. The only difference is that the $c$ parameter appears slightly increased, from 19.81 to $19.86 \AA$. The second phase has a significantly increased $a(\sim 4.44 \AA)$ and decreased $c$ parameter $(\sim 19.58 \AA)$. In the following we designate this phase as $\mathrm{Eu}_{3} \mathrm{Si}_{4} \mathrm{H}_{2}$. Rietveld plots are shown as supporting information, Figure A1. The refinement results are contained in Tables 1 and 2 which also include the structure parameters of $\mathrm{Eu}_{3} \mathrm{Si}_{4}$ obtained from single crystal X-ray diffraction data, as reported in the literature [13]. There is good agreement between our parameters from powder refinement and the reported ones. Table A1 (supporting information) lists interatomic distances.

To elucidate the hydrogenation pathway and to possibly shed light into the formation of two phases when hydrogenating at $300{ }^{\circ} \mathrm{C}$, an in-situ synchrotron PXRD experiment was performed. An overview of the results from this experiment can be seen in Figure 4 and Table 3. In contrast with the starting material used for the autoclave hydrogenation experiments, the $\mathrm{Eu}_{3} \mathrm{Si}_{4}$ sample synthesized for the in-situ experiment contained $6.1 \% \mathrm{EuSi}_{2}$ impurity (see Figure A2 and Table A2, supporting information). EuSi 2 does not absorb hydrogen and its presence did not hamper the analysis of data. The sample was subjected to a hydrogen atmosphere of $30 \mathrm{bar}$ and subsequently heated to $400{ }^{\circ} \mathrm{C}$ at a rate of $5{ }^{\circ} \mathrm{C} / \mathrm{min}$, 
dwelled for $5 \mathrm{~min}$, and then cooled back to room temperature at a rate of $5{ }^{\circ} \mathrm{C} / \mathrm{min}$. (we remind that autoclave experiments applied a dwelling time of $24 \mathrm{~h}$ ). A small but significant increase in the unit cell volume was noticed already at the start of the experiment. This indicates that $\mathrm{Eu}_{3} \mathrm{Si}_{4}$ absorbs hydrogen at room temperature, which is in agreement with the observation from the autoclave experiments (cf. Figure 2).

Upon heating, the actual transformation into a hydride phase started at $90{ }^{\circ} \mathrm{C}$ (after $0.25 \mathrm{~h}$ ) as indicated by the appearance of additional diffraction lines - and was completed at $140{ }^{\circ} \mathrm{C}$ (after $0.42 \mathrm{~h}$ ), as indicated by the vanished reflections from $\mathrm{Eu}_{3} \mathrm{Si}_{4}$. The lattice parameters of the obtained hydride phase are $a \approx 4.4 \AA, b \approx 4 \AA, c \approx 19.9 \AA$ and thus (considering also thermal expansion) relate well to those of phase $\mathrm{Eu}_{3} \mathrm{Si}_{4} \mathrm{H}_{2+x}$ obtained from the autoclave hydrogenations. Interestingly, upon heating beyond $180{ }^{\circ} \mathrm{C}$ (i. e. after $0.55 \mathrm{~h}$ ) the $c$ axis of the hydride phase contracted continuously, and was reduced by $0.6 \AA$ when reaching $400{ }^{\circ} \mathrm{C}$. The $c$ axis contraction was paralleled by a slight expansion of the $a$ axis (by $0.1 \AA$ ). This behavior was reversible upon cooling. Figure 5 depicts some detailed diffraction patterns. At $100{ }^{\circ} \mathrm{C}$ the pattern represents a phase mixture between $\mathrm{Eu}_{3} \mathrm{Si}_{4}$ and $\mathrm{Eu}_{3} \mathrm{Si}_{4} \mathrm{H}_{2+x}$. Characteristic of the latter phase is the pair of reflections centered at $\mathrm{Q} \approx 2.2 \AA^{-1}$ where $\mathrm{Eu}_{3} \mathrm{Si}_{4}$ has a single reflection. The diffraction patterns at $250{ }^{\circ} \mathrm{C}$ upon heating and cooling appear virtually identical. The pattern obtained at $400{ }^{\circ} \mathrm{C}$ yields the lattice parameters $a \approx 4.51, b \approx 4.0, c \approx$ $19.31 \AA$, which are rather different from $\mathrm{Eu}_{3} \mathrm{Si}_{4} \mathrm{H}_{2+x}$. Back at room temperature, values of the lattice parameters corresponded closely to those of $\mathrm{Eu}_{3} \mathrm{Si}_{4} \mathrm{H}_{2+x}$ obtained in the autoclave experiment at $300{ }^{\circ} \mathrm{C}$ (i.e. sample $\mathrm{Eu}_{3} \mathrm{Si}_{4} \_\mathrm{H}_{2} \_300 \mathrm{C}$, cf. Tables 1 and 3).

To sum up the salient observations with the in-situ experiment: there is an initial formation of a hydride in the temperature interval $90-140{ }^{\circ} \mathrm{C}$, which upon further heating displays continuous variation of the $c$ and $a$ lattice parameters. These variations are reversible and the initially formed hydride is regained when cooling to room temperature. We conjecture that the initially formed phase corresponds to $\mathrm{Eu}_{3} \mathrm{Si}_{4} \mathrm{H}_{2+x}$ obtained in autoclave hydrogenation experiments at $100-200{ }^{\circ} \mathrm{C}$. At higher temperatures the hydrogen content is reduced and the phase seen at $400{ }^{\circ} \mathrm{C}$ in the in-situ experiment relates to second phase obtained in the $300{ }^{\circ} \mathrm{C}$ autoclave hydrogenation experiment, $\mathrm{Eu}_{3} \mathrm{Si}_{4} \mathrm{H}_{\sim 2}$. For unknown reasons, a quenchable form of $\mathrm{Eu}_{3} \mathrm{Si}_{4} \mathrm{H}_{\sim 2}$ can only be obtained after prolonged sintering at temperatures above $200{ }^{\circ} \mathrm{C}$.

As a next step we investigated the thermal stability/desorption behavior of $\mathrm{Eu}_{3} \mathrm{Si}_{4} \mathrm{H}_{2+x}$ by exposing parts of the sample $\mathrm{Eu}_{3} \mathrm{Si}_{4} \_\mathrm{H}_{2} \_200 \mathrm{C}$ to a dynamic vacuum at elevated temperatures. Results are compiled in Figure A3 in the supporting information. The $\mathrm{Eu}_{3} \mathrm{Si}_{4} \mathrm{H}_{2+x}$ phase was essentially maintained up to $200{ }^{\circ} \mathrm{C}$. At $300{ }^{\circ} \mathrm{C}$ a changed diffraction pattern was obtained with a weaker crystallinity. Interestingly, there is strong indication that $\mathrm{Eu}_{3} \mathrm{Si}_{4} \mathrm{H}_{\sim 2}$ partially formed during the $300{ }^{\circ} \mathrm{C}$ desorption experiment. $\mathrm{Eu}_{3} \mathrm{Si}_{4}$ did not reform in desorption experiments. Thus, the hydrogenation of $\mathrm{Eu}_{3} \mathrm{Si}_{4}$ to $\mathrm{Eu}_{3} \mathrm{Si}_{4} \mathrm{H}_{2+x}$ is not reversible. Raman and IR spectra of $\mathrm{Eu}_{3} \mathrm{Si}_{4}$ and $\mathrm{Eu}_{3} \mathrm{Si}_{4} \mathrm{H}_{2+x}$ are essentially featureless which indicates that both phases are metals.

Pressure composition isotherms (PCIs) measurements were attempted in order to determine the hydrogen content of $\mathrm{Eu}_{3} \mathrm{Si}_{4} \mathrm{H}_{2+x}$. It was found that the sample absorbs hydrogen within a 
single step (single plateau pressure) below 3 bar at 250 and $300{ }^{\circ} \mathrm{C}$ and the equilibrium pressure of the absorption plateau is very low and therefore below the detectable limits of the instrument. The maximum hydrogen capacity only reached $1.7 \mathrm{H} / \mathrm{f}$.u. under these conditions, most probably due to kinetic limitation (see Figure A4). Diffraction analysis of the PCI samples conducted at 250 and $300{ }^{\circ} \mathrm{C}$ showed the presence of a phase mixture, analogous to the sample $\mathrm{Eu}_{3} \mathrm{Si}_{4}{ }_{-} \mathrm{H}_{2} \_300 \mathrm{C}$ (Table A3). This is not surprising since the equilibrium times during PCI measurements ( 2000 min) are similar to the dwelling time applied in the autoclave hydrogenation experiments $(24 \mathrm{~h})$, thus supporting the conjecture that the formation of a quenchable phase $\mathrm{Eu}_{3} \mathrm{Si}_{4} \mathrm{H}_{2}$ is associated with a slow kinetics.

\subsection{Structural variations and energetics of $H$ incorporation}

In the following we compare the structures of $\mathrm{Eu}_{3} \mathrm{Si}_{4} \mathrm{H}_{2+x}$ and $\mathrm{Eu}_{3} \mathrm{Si}_{4}$ (cf. Tables 1-3). The $a$ lattice parameter is the stacking direction of hexagon ring ribbons. With respect to $\mathrm{Eu}_{3} \mathrm{Si}_{4}$ this parameter is contracted by about $5 \%$ for $\mathrm{Eu}_{3} \mathrm{Si}_{4} \mathrm{H}_{2+x}$ (from 4.62 to $4.4 \AA$ ) and by about $4 \%$ for $\mathrm{Eu}_{3} \mathrm{Si}_{4} \mathrm{H}_{\sim 2}$. The $b$ parameter (i.e. the direction of ribbons) is virtually unaffected upon hydride formation, whereas the $c$ parameter increases considerably, from 18.24 to $19.81-19.87 \AA$ for $\mathrm{Eu}_{3} \mathrm{Si}_{4} \mathrm{H}_{2+x}$ and to $19.58 \AA$ for $\mathrm{Eu}_{3} \mathrm{Si}_{4} \mathrm{H}_{\sim 2}$. The associated volume increase of the unit cells are about 4.2 and $3.5 \%$, respectively.

The high neutron capture cross section of Eu makes the application of neutron diffraction for structural analysis of $\mathrm{Eu}_{3} \mathrm{Si}_{4} \mathrm{H}_{2+x}$ difficult, requiring samples with isotopically enriched ${ }^{153} \mathrm{Eu}$. For identifying possible locations for $\mathrm{H}$ atoms, we therefore utilized our experience with $\mathrm{REGaH}_{2-\mathrm{x}}[10,11]$. The precursor Zintl phases REGa crystallize with the $\mathrm{CrB}$ structure $[15,16,17]$. As discussed in the introduction, the $\mathrm{Eu}_{3} \mathrm{Si}_{4}$ structure can be considered built from slabs of CrB structure. The arrangement of Eu2 atoms in "Si" free layers corresponds to an array of edge sharing tetrahedra (cf. Figure 1). The centers of these tetrahedra are occupied in $\mathrm{REGaH}_{2-\mathrm{x}}$ by one kind of $\mathrm{H}$ atoms (H1). This is similar to hydrides with the $\mathrm{ZrCuSiAs}$ structure type (e.g. $\mathrm{CeCoSiH}$ ) [31]. Assuming the same scenario for $\mathrm{Eu}_{3} \mathrm{Si}_{4}$ one arrives at an interstitial hydride $\mathrm{Eu}_{3} \mathrm{Si}_{4} \mathrm{H}_{2}$. The centers of $\mathrm{Eu}_{2}{ }_{4}$ tetrahedra corresponds to a site $4 \mathrm{i}(0,0, \mathrm{z}) \mathrm{z} \approx$ 0.25 in space group Immm. The structure parameters of the $\mathrm{Eu}_{3} \mathrm{Si}_{4} \mathrm{H}_{2}$ model were subsequently optimized by non spin polarized DFT calculations. To validate the simplified non spin polarized approach, we also subjected the $\mathrm{Eu}_{3} \mathrm{Si}_{4}$ structure to DFT optimization. The results are given in Tables 4 and $\mathrm{A} 4$. We note that the $\mathrm{Immm}$ structure of $\mathrm{Eu}_{3} \mathrm{Si}_{4}$ is excellently reproduced by DFT structure optimization (cf. Tables 1, 2, 4).

The DFT optimized structure for the $\mathrm{Eu}_{3} \mathrm{Si}_{4} \mathrm{H}_{2}$ model (space group Immm) is shown in Figure 6. The incorporation of $\mathrm{H}$ into the $\mathrm{Eu}_{2}$ tetrahedral site in $\mathrm{Eu}_{3} \mathrm{Si}_{4}$ is clearly energetically favorable. The calculated energy for the reaction $\mathrm{Eu}_{3} \mathrm{Si}_{4}+\mathrm{H}_{2} \rightarrow \mathrm{Eu}_{3} \mathrm{Si}_{4} \mathrm{H}_{2}$ is $-0.918 \mathrm{eV}$. However, the stabilization $\mathrm{E} / \mathrm{H}=-0.459 \mathrm{eV}$ is lower compared to $\mathrm{REGaH}_{2-\mathrm{x}}(\mathrm{E} / \mathrm{H} 1=-0.76$ $\mathrm{eV} / \mathrm{H}$ ) because in the latter, $\mathrm{H}$ (in the equivalent $\mathrm{H} 1$ position) becomes situated in an environment of trivalent RE. Further, the DFT optimized structure of $\mathrm{Eu}_{3} \mathrm{Si}_{4} \mathrm{H}_{2}$ structure shows evidently the experimentally observed trend in the lattice parameter variations, that is, a contracted $a$, constant $b$ and expanded $c$ parameter with respect to $\mathrm{Eu}_{3} \mathrm{Si}_{4}$. Importantly, the values are rather close to those of $\mathrm{Eu}_{3} \mathrm{Si}_{4} \mathrm{H}_{\sim 2}$ from which we infer the approximate 
composition of this phase. At the same time we are unable to provide an explanation as to why a quenchable form of $\mathrm{Eu}_{3} \mathrm{Si}_{4} \mathrm{H}_{2}$ was only obtained in sintering experiments.

In contrast with the other RE metals, Eu can easily change between the di- and trivalent state. Several scenarios are possible when going from $\mathrm{Eu}_{3} \mathrm{Si}_{4}$ to $\mathrm{Eu}_{3} \mathrm{Si}_{4} \mathrm{H}_{2}$. Importantly, in interstitial hydrides $\mathrm{H}$ behaves typically hydridic and, thus, interstitial hydride formation can be accompanied by both, oxidation of the polyanion and oxidation of $\mathrm{Eu}^{2+}$. This is sketched in Figure 7. If $\mathrm{Eu}^{2+}$ was oxidized, a block $\left[\mathrm{Eu}_{2}{ }_{2} \mathrm{H}_{2}\right]$ would carry four positive charges and no changes are expected for the polyanion. If $\mathrm{Eu}^{2+}$ present in $\mathrm{Eu}_{3} \mathrm{Si}_{4}$ is not oxidized, a block $\left[\mathrm{Eu}_{2} \mathrm{H}_{2}\right]$ carries two positive charges. Assuming charge balance, the Si hexagon chain becomes oxidized and may respond to this by developing $\pi$-bonding. This scenario is indicated when comparing the $\mathrm{Si}-\mathrm{Si}$ distances in the DFT optimized structures of $\mathrm{Eu}_{3} \mathrm{Si}_{4}$ and $\mathrm{Eu}_{4} \mathrm{Si}_{4} \mathrm{H}_{2}$ (Table A4). Both distances, $\mathrm{Si} 1-\mathrm{Si} 2$ and $\mathrm{Si} 2-\mathrm{Si} 2$ reduce slightly, by $0.02-0.03 \AA$, when going from $\mathrm{Eu}_{3} \mathrm{Si}_{4}$ to $\mathrm{Eu}_{3} \mathrm{Si}_{4} \mathrm{H}_{2}$.

The considerably larger $c$ parameter of $\mathrm{Eu}_{3} \mathrm{Si}_{4} \mathrm{H}_{2+x}$ compared to $\mathrm{Eu}_{3} \mathrm{Si}_{4} \mathrm{H}_{\sim 2}$ (and compared to the DFT optimized structure for $\mathrm{Eu}_{3} \mathrm{Si}_{4} \mathrm{H}_{2}$ ) point to the incorporation of additional $\mathrm{H}$ in $\mathrm{Eu}_{3} \mathrm{Si}_{4}$, that is, a composition $\mathrm{Eu}_{3} \mathrm{Si}_{4} \mathrm{H}_{2+x}$ is attained upon hydride formation below $200{ }^{\circ} \mathrm{C}$. This situation would remind of REGa for which additional $\mathrm{H}$, on the position $\mathrm{H} 2$, is inserted between $\mathrm{Ga}$ atoms of neighboring zigzag chains [10,11]. The $\mathrm{H} 2$ site is only partially occupied (2/3) in the hydrides $\mathrm{REGaH}_{1.66}$. Importantly, $\mathrm{H} 1$ (fully occupied) and $\mathrm{H} 2$ are chemically different. The former is interstitial, primarily leading to an oxidation of the polyanion, the latter is a part of the polyanion [10].

Thus, again guided by REGa, we indentified the $4 \mathrm{i}$ position $(0,0, \sim 0.87)$ between two $\mathrm{Si} 2$ atoms of neighboring hexagon rings as a possible location for additional $\mathrm{H}$. This position centers at the same time Eu2 $2_{2} \mathrm{Eu} 1$ triangles (cf. Figure 1a). The resulting $\mathrm{Si}_{2} \mathrm{Eu}_{3}$ trigonal bipyramidal environment is comparable to the $\mathrm{Ga}_{2} \mathrm{La}_{3}$ environment in the recently reported $\mathrm{H}$ disordered hydride $\mathrm{LaGa}_{2} \mathrm{D}_{0.7}$, which is based on the $\mathrm{AlB}_{2}$ structure type [32]. Subsequent DFT optimization of the structure parameters yielded a monoclinic structure for the hydride $\mathrm{Eu}_{3} \mathrm{Si}_{4} \mathrm{H}_{4}$. The relaxed structure of this hydride is shown in Figure 8a. It features a polyanion $\left[\mathrm{Si}_{2} \mathrm{Si}_{2} \mathrm{H}_{2}\right]^{4-}$ in which $\mathrm{H} 2$ is regularly bonded to $\mathrm{Si} 2(\mathrm{~d}(\mathrm{Si} 2-\mathrm{H} 2)=1.61 \AA)$. At the same time, planar hexagon rings corrugate slightly and attain a chair conformation. The situation is strikingly similar to recently discovered $\mathrm{BaSiH}_{2-\mathrm{x}}$ and $\mathrm{SrSiH}_{5 / 3-\mathrm{x}}$ with polyanionic zigzag chains $[\mathrm{SiH}]^{-}$and ribbons $\left[\mathrm{Si}_{2} \mathrm{H}\right]^{2-}$, respectively $[8,9]$. In these compounds (calculated) $\mathrm{Si}-\mathrm{H}$ distances are in a range 1.64 to $1.66 \AA$.

The reaction energy for the step $\mathrm{Eu}_{3} \mathrm{Si}_{4} \mathrm{H}_{2}+\mathrm{H}_{2} \rightarrow \mathrm{Eu}_{3} \mathrm{Si}_{4} \mathrm{H}_{4}$ is still negative, $-0.395 \mathrm{eV}$, but it is clear that the $\mathrm{H} 2$ position is far less favorable compared to $\mathrm{H} 1$. The structure of $\mathrm{Eu}_{3} \mathrm{Si}_{4} \mathrm{H}_{4}$ is monoclinic, but the lattice metrics is close to orthorhombic. The monoclinic angle of a body centered lattice, which is preferably used when comparing to the Immm structures of $\mathrm{Eu}_{3} \mathrm{Si}_{4}$ and $\mathrm{Eu}_{3} \mathrm{Si}_{4} \mathrm{H}_{2}$, is $91.9^{\circ}$ (cf. Table 4). The $c$ lattice parameter of $\mathrm{Eu}_{3} \mathrm{Si}_{4} \mathrm{H}_{4}$ is considerably increased compared to $\mathrm{Eu}_{3} \mathrm{Si}_{4} \mathrm{H}_{2}$, to $19.88 \AA$, whereas the $a$ and $b$ parameters are essentially the same. Thus, it appears that a closer agreement to the experimental values was obtained (cf. Table 1). We also considered an ordered model $\mathrm{Eu}_{3} \mathrm{Si}_{4} \mathrm{H}_{3}$ with half of the $\mathrm{Si} 2$ atoms 
terminated by $\mathrm{H} 2$ type atoms. Its DFT optimized structure, which also is monoclinic, is shown in Figure 8b. The increase of the $c$ parameter with respect to $\mathrm{Eu}_{3} \mathrm{Si}_{4}$ is less pronounced (19.61 $\AA$ ).

The monoclinic symmetry of the calculated models $\mathrm{Eu}_{3} \mathrm{Si}_{4} \mathrm{H}_{4}$ and $\mathrm{Eu}_{3} \mathrm{Si}_{4} \mathrm{H}_{3}$ is a consequence of the puckering of hexagon layers. The symmetry reduction is clearly not observed in the PXRD pattern of e.g. $\mathrm{Eu}_{3} \mathrm{Si}_{4} \mathrm{H}_{2} \_\mathrm{H}_{2} \_200 \mathrm{C}$ (cf. Figures 3 and A1). Therefore it can be concluded that the additional $\mathrm{H}$ in $\mathrm{Eu}_{3} \mathrm{Si}_{4} \mathrm{H}_{2+x}$ probably incorporates in a more complicated, disordered, fashion. A similar situation has been described for $\mathrm{LaGa}_{2} \mathrm{D}_{0.7}$ [32].

\subsection{H-induced magnetic property changes}

The ZFC and FC magnetization of $\mathrm{Eu}_{3} \mathrm{Si}_{4}$ and $\mathrm{Eu}_{3} \mathrm{Si}_{4} \mathrm{H}_{2+x}$ (sample $\mathrm{Eu}_{3} \mathrm{Si}_{4} \_\mathrm{H}_{2}$ 200C) as a function of temperature in an applied field of $4 \mathrm{kA} / \mathrm{m}$ is shown in Figure 9a. The Zintl phase $\mathrm{Eu}_{3} \mathrm{Si}_{4}$ has two noteworthy features, a sharp increase in the magnetization at $120 \mathrm{~K}$ and another pronounced feature at about $40 \mathrm{~K}$. In Ref. [13] the same behavior was observed, and the authors suggested a ferromagnetic ordering at $117 \mathrm{~K}$ for the Eu2 site and a consecutive ferromagnetic ordering of the Eu1 site at about $40 \mathrm{~K}$. However, with a weak antiferromagnetic coupling between the two substructures which gives rise to a ferrimagnetic total structure at low temperatures. Upon hydrogenation it can be observed that the ferromagnetic transition at $120 \mathrm{~K}$ disappears, indicating that the hydrogenation disrupts the ordering of the Eu2 moments at $120 \mathrm{~K}$. Since SQUID magnetometry is very sensitive to magnetic impurities (especially ferromagnetic ones) it is also clear that there is no trace of the original ferromagnetic $\mathrm{Eu}_{3} \mathrm{Si}_{4}$ phase in the hydride sample.

The ZFC and FC thermomagnetic curves for the $\mathrm{Eu}_{3} \mathrm{Si}_{4} \mathrm{H}_{2+x}$ sample in Figure 9a indicates a para- to antiferromagnetic transition at about $40 \mathrm{~K}$. However, with some uncompensated spins in the antiferromagnetic phase giving rise to an excess moment as seen from the separation of the ZFC and FC curves below the transition temperature. The magnetization as a function of field behavior at $6 \mathrm{~K}$ is complex and exhibits a second magnetic hysteresis loop at high fields (above $3000 \mathrm{kA} / \mathrm{m}$ ), see Figure 9b). A similar behavior to the data presented in Figure $9 \mathrm{~b}$ has been observed in single crystals of the antiferromagnet UIrSi 3 , which crystallizes in the tetragonal $\mathrm{BaNiSn}_{3}$ structure type [33]. The magnetic moments in $\mathrm{UIrSi}_{3}$ order ferromagnetically in the $a b$ plane with the moments aligned along the $c$ axis. The ferromagnetic planes order then antiferromagnetically with respect to each other, yielding a net antiferromagnetic structure. Upon application of a sufficiently large magnetic field along the $c$ axis (easy axis), UIrSi 3 exhibits a metamagnetic transition to a ferromagnetic configuration. No metamagnetic transition was observed upon application of the magnetic field along the $a$ axis. Even though the behavior observed in $\mathrm{UIrSI}_{3}$ agrees well with the data presented in Figure $9 \mathrm{~b}$ (if the polycrystallinity of the $\mathrm{Eu}_{3} \mathrm{Si}_{4} \mathrm{H}_{2+x}$ sample is taken into account), it cannot with certainty be concluded that this is the origin of the observed effect from the collected data. From Curie-Weiss fits it was found that $\mathrm{p}_{\mathrm{eff}} \approx 7.5 \mu_{\mathrm{B}}\left(\sim 7.2\right.$ for $\mathrm{Eu}_{3} \mathrm{Si}_{4}$ and $\sim 7.7$ for the hydrogenated sample), indicating $4 \mathrm{f}^{7} \mathrm{Eu}^{2+}$ for both samples $\left(\mathrm{Eu}^{2+} \sim 8\right.$ and $\mathrm{Eu}^{3+} \sim 3.4$ $\left.\mu_{\mathrm{B}}\right)$. The Curie-Weiss temperatures $\left(\Omega_{C W}\right)$ are $\sim 110$ and $\sim 5 \mathrm{~K}$ for $\mathrm{Eu}_{3} \mathrm{Si}_{4}$ and $\mathrm{Eu}_{3} \mathrm{Si}_{4} \mathrm{H}_{2+x}$ 
respectively. The drastic change in $\Omega_{C W}$ further underlines the disruptive effect that hydrogen has on the magnetic interaction in $\mathrm{Eu}_{3} \mathrm{Si}_{4}$.

\section{Conclusions}

$\mathrm{Eu}_{3} \mathrm{Si}_{4}$ absorbs hydrogen already at room temperature when exposing the material to a hydrogen atmosphere of 30 bar. Structural analysis by a combination of X-Ray powder diffraction and DFT modeling suggests that at temperatures up to $200{ }^{\circ} \mathrm{C}$ a hydride $\mathrm{Eu}_{3} \mathrm{Si}_{4} \mathrm{H}_{2+\mathrm{x}}$ is formed, whereas sintering at higher temperatures $\left(300{ }^{\circ} \mathrm{C}\right)$ affords a hydride with lower hydrogen content, $\mathrm{Eu}_{3} \mathrm{Si}_{4} \mathrm{H}_{\sim 2}$. $\mathrm{Eu}_{3} \mathrm{Si}_{4} \mathrm{H}_{2+x}$ desorbs $\mathrm{H}$ irreversibly above $\mathrm{T}=200{ }^{\circ} \mathrm{C}$. The ferromagnetic properties of $\mathrm{Eu}_{3} \mathrm{Si}_{4}$ are effectively quenched upon hydrogenation to $\mathrm{Eu}_{3} \mathrm{Si}_{4} \mathrm{H}_{2+x}$. The effective bohrmagneton number of $\mathrm{Eu}_{3} \mathrm{Si}_{4} \mathrm{H}_{2+x}$ is close to that of $\mathrm{Eu}_{3} \mathrm{Si}_{4}$ above $\mathrm{T}_{c}$, indicating that Eu possesses the same oxidation state (i.e. +2$)$ in both systems.

Acknowledgement. This work has been supported by the Swedish research council and the NordForsk project "Neutrons for multifunctional hydrides (FunHy)". 


\section{References}

[1] S. M. Kauzlarich, Chemistry, Structure, and Bonding of Zintl Phases and Ions, Wiley, 1996.

[2] R. Nesper, The Zintl-Klemm Concept - A Historical Survey, Z. Anorg. Allg. Chem. 640 (2014) 2639-2648. doi:10.1002/zaac.201400403.

[3] S. C. Sevov, Zintl phases, in: J. H. Westbrook, R. L. Fleischer (Eds.), Intermetallic Compounds: Principles and Practice, John Wiley and Sons Ltd, 2002, pp. 113-132.

[4] U. Häussermann, V. F. Kranak, K. Puhakainen, Hydrogenous Zintl Phases: Interstitial Versus Polyanionic Hydrides, in: T. F. Fässler (Ed.), Zintl phases: Principles and recent developments, Structure and Bonding 139 (2011), 143-161. doi: 10.1007/430_2010_20.

[5] U. Häussermann, Coexistence of hydrogen and polyanions in multinary main group element hydrides, Z. Kristallogr. 223 (2008) 628-635. doi:10.1524/zkri.2008.1016.

[6] T. Björling, D. Noreus, K. Jansson, M. Andersson, E. Leonova, M. Eden, U. Hålenius, U. Häussermann, SrAlSiH: A Polyanionic Semiconductor Hydride, Angew. Chem. Int. Ed. 44 (2005) 7269-7273. doi:10.1002/anie.200502090.

[7] M. H. Lee, T. Björling, B. C. Hauback, T. Utsumi, D. Moser, D. Bull, D. Noreus, O. F. Sankey, U. Häussermann, Crystal structure, electronic structure, and vibrational properties of $\mathrm{MAlSiH}(\mathrm{M}=\mathrm{Ca}, \mathrm{Sr}, \mathrm{Ba})$ : Hydrogenation-induced semiconductors from the AlB2-type alloys MAlSi, Phys. Rev. B 78 (2008) 195209. doi:10.1103/PhysRevB.78.195209.

[8] H. Auer, R. Guehne, M. Bertmer, S. Weber, P. Wenderoth, T. C. Hansen, J. Haase, H. Kohlmann, Hydrides of Alkaline Earth-Tetrel (AeTt) Zintl Phases: Covalent Tt-H Bonds from Silicon to Tin, Inorg. Chem. 56 (2017) 1061-1071. doi:10.1021/acs.inorgchem.6b01944.

[9] H. Auer, R. Schlegel, O. Oeckler, H. Kohlmann, Structural and Electronic Flexibility in Hydrides of Zintl Phases with Tetrel - Hydrogen and Tetrel - Tetrel Bonds, Angew. Chem. Int. Ed. 56 (2017) 12344-12347. doi:10.1002/anie.201706523.

[10] J. Ångström, R. Johansson, T. Sarkar, M. H. Sørby, C. Zlotea, M. S. Andersson, P. Nordblad, R. H. Scheicher, U. Häussermann, M. Sahlberg, Hydrogenation-Induced Structure and Property Changes in the Rare-Earth Metal Gallide NdGa: Evolution of a $[\mathrm{GaH}] 2-$ Polyanion Containing Peierls-like Ga-H Chains, Inorg. Chem. 55 (2016) 345-352. doi:10.1021/acs.inorgchem.5b02485.

[11] R. Nedumkandathil, V. F. Kranak, R. Johansson, J. Angström, O. Balmes, M. S. Andersson, P. Nordblad, R. H. Scheicher, M. Sahlberg, U. Häussermann, Hydrogenation induced structure and property changes in GdGa, J. Solid. State Chem. 239 (2016) 184-191. doi:10.1016/j.jssc.2016.04.028.

[12] H. Auer, R. Nedumkandathil, U. Häussermann, H. Kohlmann, The Hydrogenation of the Zintl Phase NdGa Studied by in situ neutron diffraction, Z. Anorg. Allg. Chem. 645 (2019) 175-181. doi:10.1002/zaac.201800459. 
[13] F. Weitzer, Y. Prots, W. Schnelle, K. Hiebl, Y. Grin, The novel silicide Eu3Si4: Structure, chemical bonding, magnetic behavior and electrical resistivity, J. Solid State Chem. 177 (2004) 2115-2121. doi:10.1016/j.jssc.2004.02.013.

[14] The structure refinement reported in ref. [13] described one of the Si atoms (2b) Si2 with a split position, indicating a slight corrugation of the Si hexagon rings. In the discussion of the experimental $\mathrm{Eu}_{3} \mathrm{Si}_{4}$ structure in this work an idealized structure with planar hexagon rings is assumed. In this structure $\mathrm{Si} 2$ is located on a position $4 \mathrm{i}(0,0.4360)$.

[15] B. Barbara, Nguyen-Van-Nhung, E. Siaud, Magnetic properties of rare earth-gallium equiatomic compounds, CR. Acad. Sci B 274 (1972) 1053-1056.

[16] H. Fujii, N. Shohata, T. Okamoto, E. Tatsumoto, Magnetic Properties of Rare Earth Gallium Compounds RGa, J. Phys. Soc. Jpn. 31 (1971) 1592-1592. doi:10.1143/JPSJ.31.1592.

[17] N. Shohata, Magnetic Properties of Rare Earth Gallium Intermetallic Compounds, J. Phys. Soc. Jpn. 42 (1977) 1873-1880. doi:10.1143/JPSJ.42.1873.

[18] A. P. Hammersley, S. O. Svensson, M. Hanfland, A. N. Fitch, D. Hausermann, Twodimensional detector software: From real detector to idealised image or two-theta scan, High Pressure Res. 14 (1996) 235-248. doi:10.1080/08957959608201408.

[19] H. M. Rietveld, A profile refinement method for nuclear and magnetic structures, J. Appl. Crystallogr. 2 (1969) 65-71. doi:10.1107/S0021889869006558.

[20] R.-C. Juan, Fullprof: A Program for Rietveld Refinement and Pattern Matching Analysis, Abstract of the Satellite Meeting on Powder Diffrac- tion of the XV Congress of the IUCr, Toulouse, France 127 (1990).

[21] P. Norby, Hydrothermal Conversion of Zeolites: An in Situ Synchrotron X-ray Powder Diffraction Study, J. Am. Chem. Soc. 119 (1997) 5215-5221. doi:10.1021/ja964245g.

[22] A. A. Coelho, Computer programs TOPAS and TOPAS-Academic: an optimization program integrating computer algebra and crystallographic objects written in $\mathrm{C}++210-218$ (2018). doi:10.1107/S1600576718000183.

[23] G. Kresse, J. Hafner, Ab initio molecular dynamics for liquid metals, Phys. Rev. B 47 (1993) 558-561. doi:10.1103/PhysRevB.47.558.

[24] G. Kresse, J. Furthmuller, Efficiency of ab-initio total energy calculations for metals and semiconductors using a plane-wave basis set, Comput. Mater. Sci. 6 (1996) 15-50. doi:10.1016/0927- 0256(96)00008-0.

[25] P. E. Blöchl, Projector augmented-wave method, Phys. Rev. B 50 (1994) 1795317979. doi:10.1103/PhysRevB.50.17953.

[26] G. Kresse, D. Joubert, From ultrasoft pseudopotentials to the projector augmented-wave method, Phys. Rev. B 59 (1999) 1758-1775. doi:10.1103/PhysRevB.59.1758. 
[27] J. P. Perdew, K. Burke, M. Ernzerhof, Generalized Gradient Approximation Made Simple, Phys. Rev. Lett. 77 (1996) 3865-3868. doi:10.1103/PhysRevLett.77.3865.

[28] J. P. Perdew, K. Burke, M. Ernzerhof, Generalized Gradient Approximation Made Simple [erratum], Phys. Rev. Lett. 78 (1997) 1396-1396. doi:10.1103/PhysRevLett.78.1396.

[29] H. J. Monkhorst, J. D. Pack, Special points for Brillouin-zone integrations, Phys. Rev. B 13 (1976) 5188-5192. doi:10.1103/PhysRevB.13.5188.

[30] H. T. Stokes, D. M. Hatch, FINDSYM: program for identifying the space-group symmetry of a crystal, J. Appl. Crystallogr. 38 (2005) 237-238. doi:10.1107/S0021889804031528.

[32] R. Pöttgen, D. Johrendt, Materials with ZrCuSiAs-type Structure, Z. Naturforsch. 63b (2008) 1135-1148. doi:10.1515/znb- 2008-1001.

[31] A. Werwein, C. Benndorf, M. Bertmer, A. Franz, O. Oeckler, H. Kohlmann, Hydrogenation properties of $\mathrm{LnAl}_{2}(\mathrm{Ln}=\mathrm{La}, \mathrm{Eu}, \mathrm{Yb}), \mathrm{LaGa}_{2}, \mathrm{LaSi}_{2}$ and the crystal structure of $\mathrm{LaGa}_{2} \mathrm{H}_{0.71(2)}$, Crystals 9 (2019) 1-12. doi:10.3390/cryst9040193.

[33] J. Valenta, F. Honda, M. Valiska, P. Opletal, J. Kastil, M. Misek, M. Divis, L. Sandratskii, J. Prchal, V. Sechovsky, Antiferromagnetism and phase transitions in $\begin{array}{lllllll}\text { noncentrosymmetric UIrSi3, } & \text { Phys. Rev. B } & 97 & \text { (2018) } & 144423 .\end{array}$ doi.org/10.1103/PhysRevB.97.144423 


\section{Figures}

Figure 1. a) Idealized crystal structure of $\mathrm{Eu}_{3} \mathrm{Si}_{4}$ (space group Immm) with polyanionic ribbons of planar hexagon rings projected approximately along the $a$ (left) and the $b$ (right) direction $[13,14]$. The arrangement of Eu2 atoms into arrays of edge condensed tetrahedra and the trigonal prismatic coordination of Eu2 around Si atoms are emphasized. b) Relation of the $\mathrm{CrB}$ and $\mathrm{Eu}_{3} \mathrm{Si}_{4}$ structures. Eu and $\mathrm{Si}$ atoms are depicted as grey and red circles, respectively.

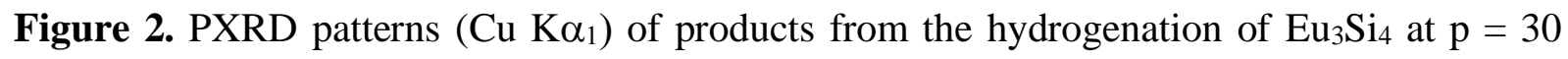
bar during $24 \mathrm{~h}$ experiments at room temperature, $100{ }^{\circ} \mathrm{C}, 200{ }^{\circ} \mathrm{C}$, and $300{ }^{\circ} \mathrm{C}$. The pattern of the $\mathrm{Eu}_{3} \mathrm{Si}_{4}$ starting material is shown as black line.

Figure 3. Synchrotron PXRD patterns $(\lambda=0.2073 \AA)$ for $\mathrm{Eu}_{3} \mathrm{Si}_{4}$ and products obtained from $24 \mathrm{~h}$ hydrogenations at $200{ }^{\circ} \mathrm{C}\left(\mathrm{Eu}_{3} \mathrm{Si}_{4} \mathrm{H}_{2}{ }_{-} 200 \mathrm{C}\right)$ and $300{ }^{\circ} \mathrm{C}\left(\mathrm{Eu}_{3} \mathrm{Si}_{4} \mathrm{H}_{2} 300 \mathrm{C}\right)$.

Figure 4. a) Densiometric view of diffraction patterns during in-situ synchrotron measurements. b) Unit cell parameters of the hydride phase obtained from sequential Rietveld refinements.

Figure 5. Selected diffraction patterns during different stages of hydrogenation (as shown in Figure 4). Reflections from the $\mathrm{EuSi}_{2}$ impurity phase are marked with asterisks (*).

Figure 6. DFT optimized crystal structure model for $\mathrm{Eu}_{3} \mathrm{Si}_{4} \mathrm{H}_{2}$.

Figure 7. Different scenarios for products from $\mathrm{Eu}_{3} \mathrm{Si}_{4}$ hydrogenation.

Figure 8. DFT optimized crystal structure models for $\mathrm{Eu}_{3} \mathrm{Si}_{4} \mathrm{H}_{4}, \mathrm{Eu}_{3} \mathrm{Si}_{4} \mathrm{H}_{3}$.

Figure 9. a) Zero field cooled and field cooled curves for $\mathrm{Eu}_{3} \mathrm{Si}_{4}$ and $\mathrm{Eu}_{3} \mathrm{Si}_{4} \mathrm{H}_{2+x}$ in an applied magnetic field $\mathrm{H}=4 \mathrm{kA} / \mathrm{m}$. b) Magnetization as a function of applied magnetic field for $\mathrm{Eu}_{3} \mathrm{Si}_{4}$ and $\mathrm{Eu}_{3} \mathrm{Si}_{4} \mathrm{H}_{2+x}$ at $6 \mathrm{~K}$. 
Figure 1.
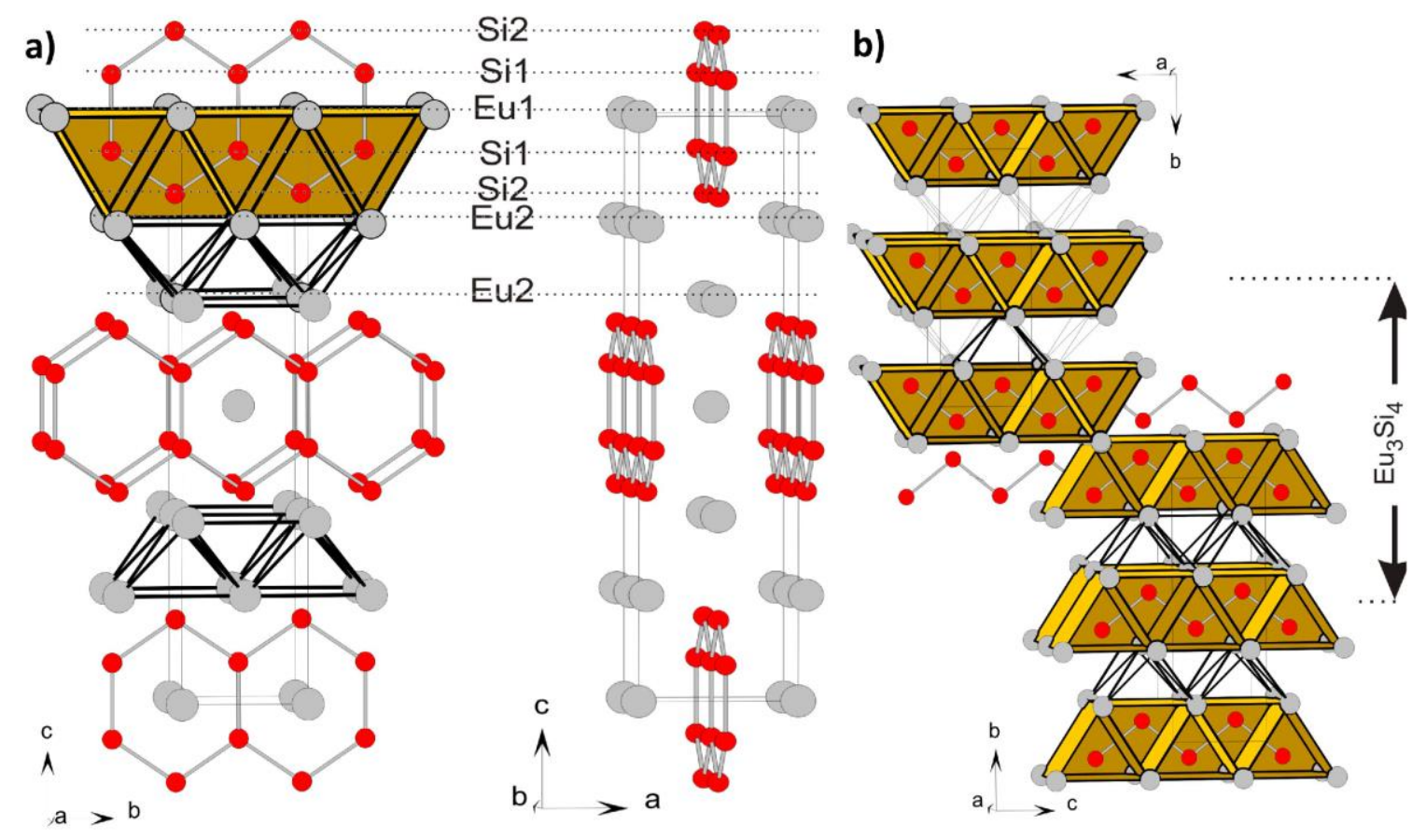

Figure 2.

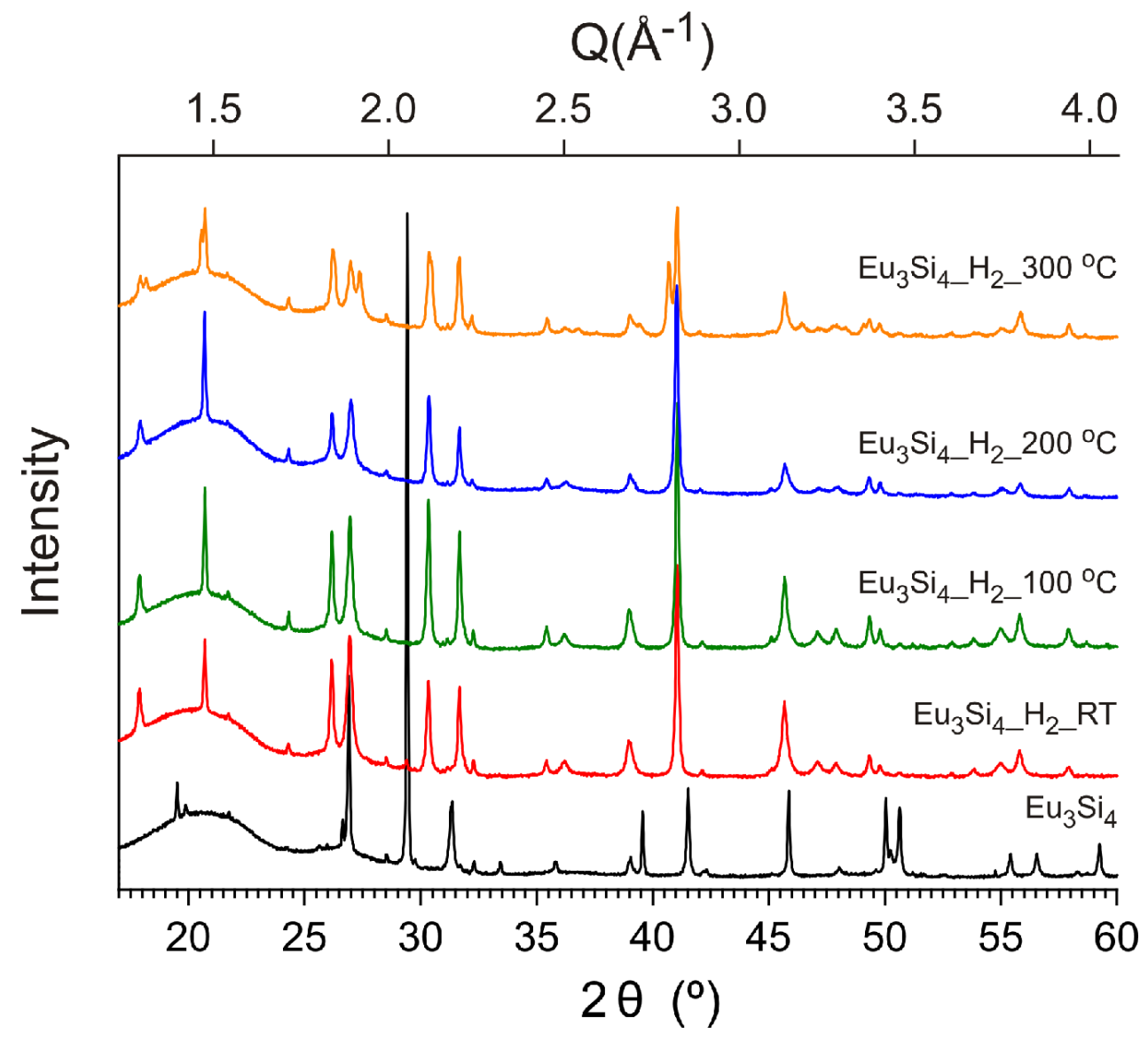


Figure 3.

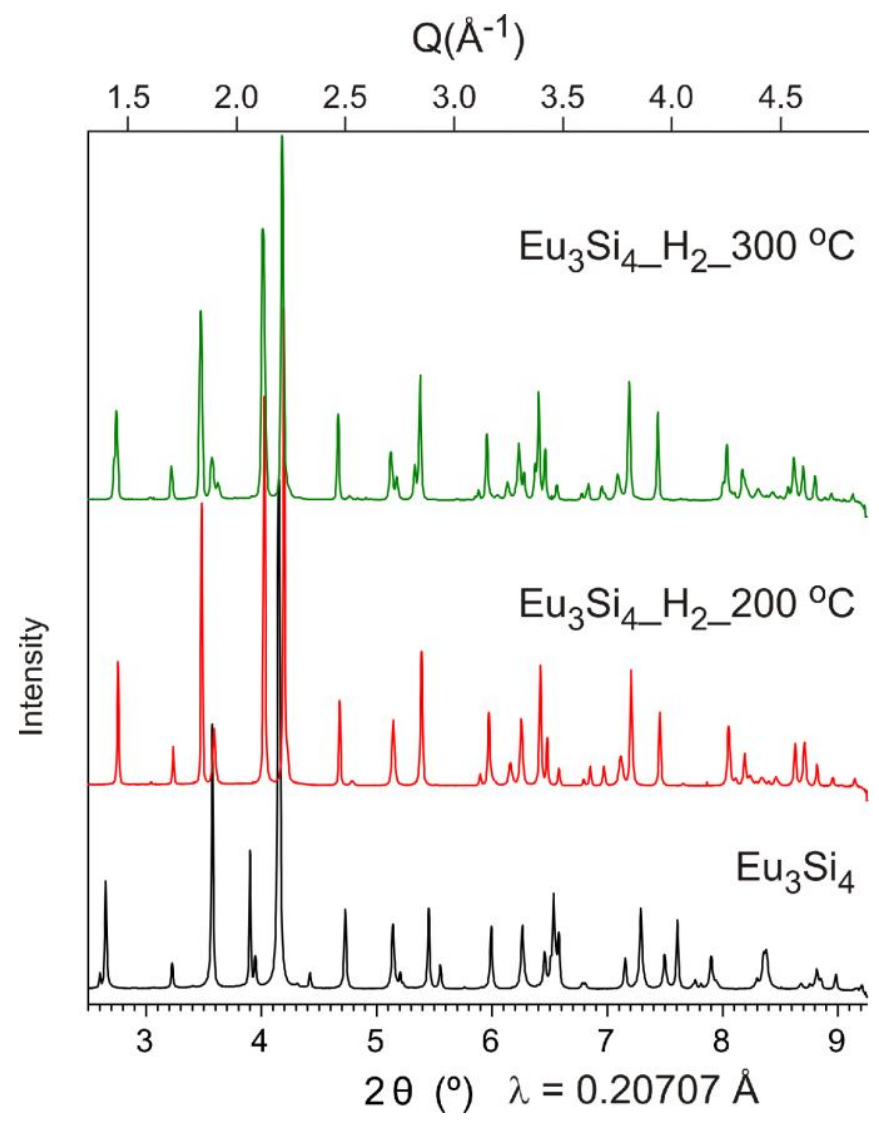


Figure 4.
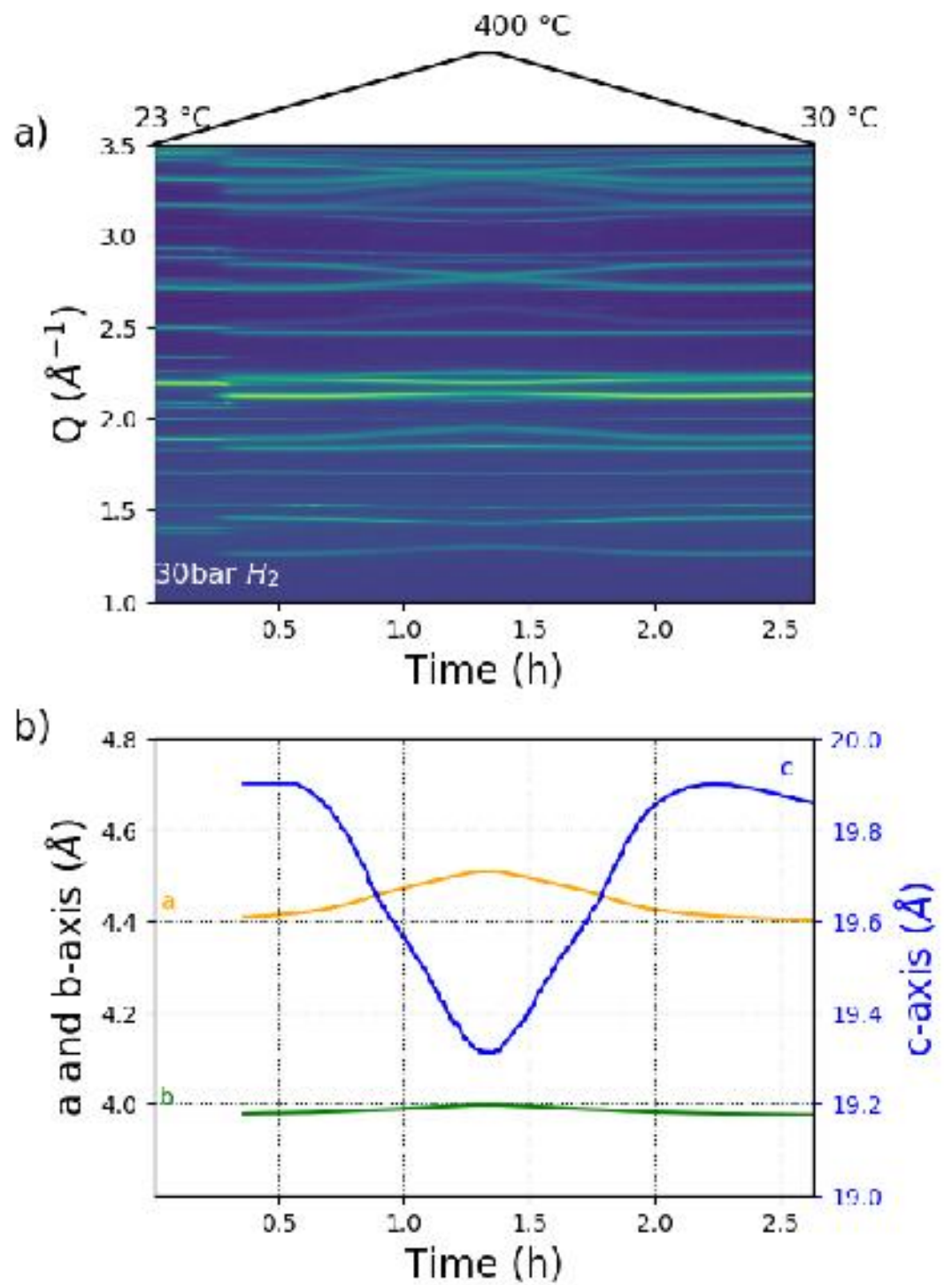
Figure 5.

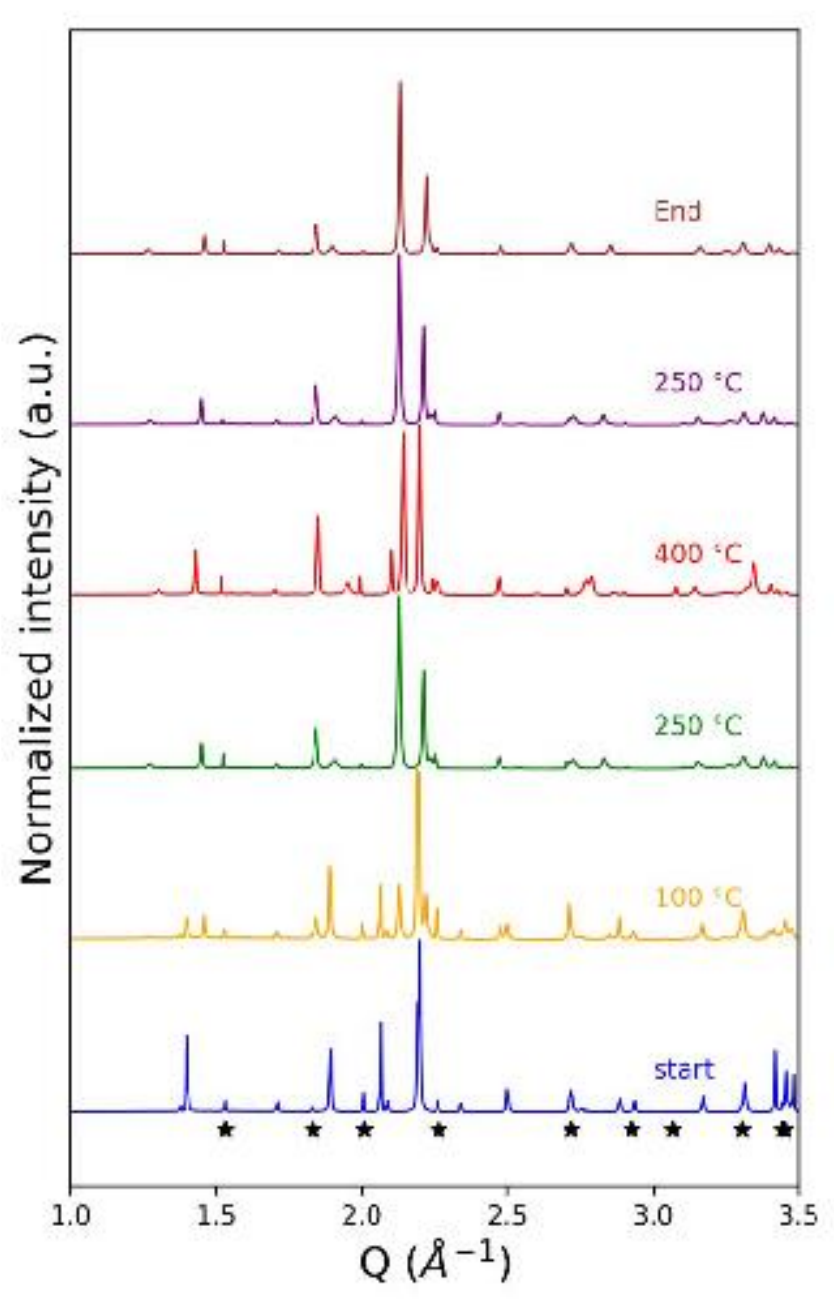


Figure 6.
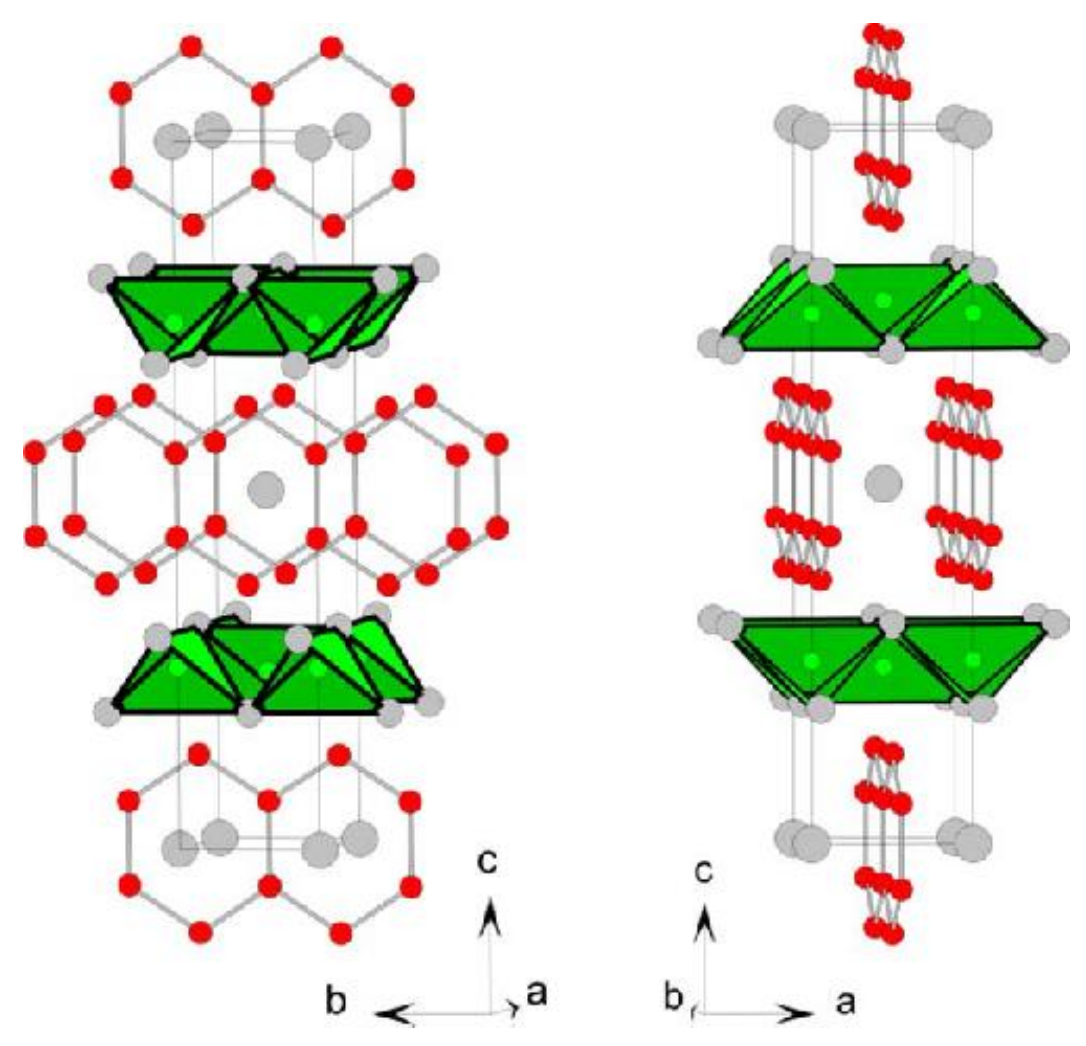
Figure 7.
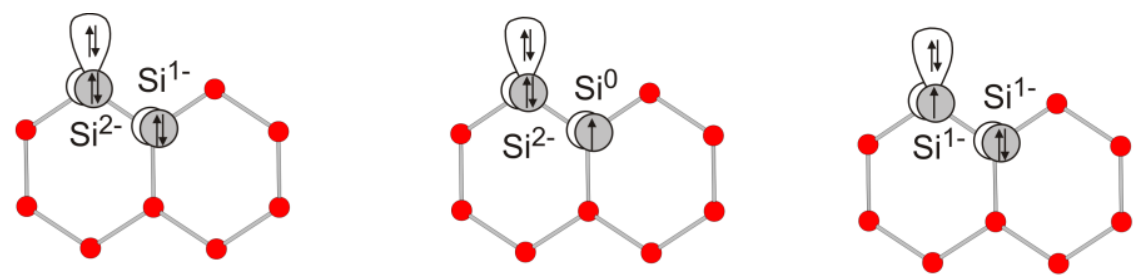

$\mathrm{Eu}_{3} \mathrm{Si}_{4} \mathrm{H}_{2}$
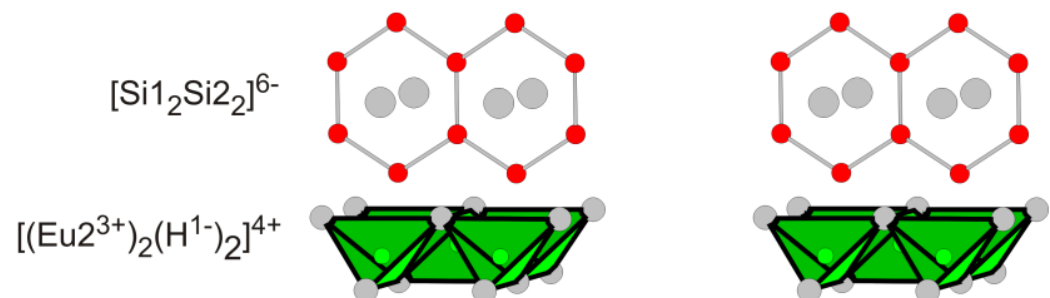

$\left[\mathrm{Si}_{2}{ }_{2} \mathrm{Si}_{2}\right]^{4-}$
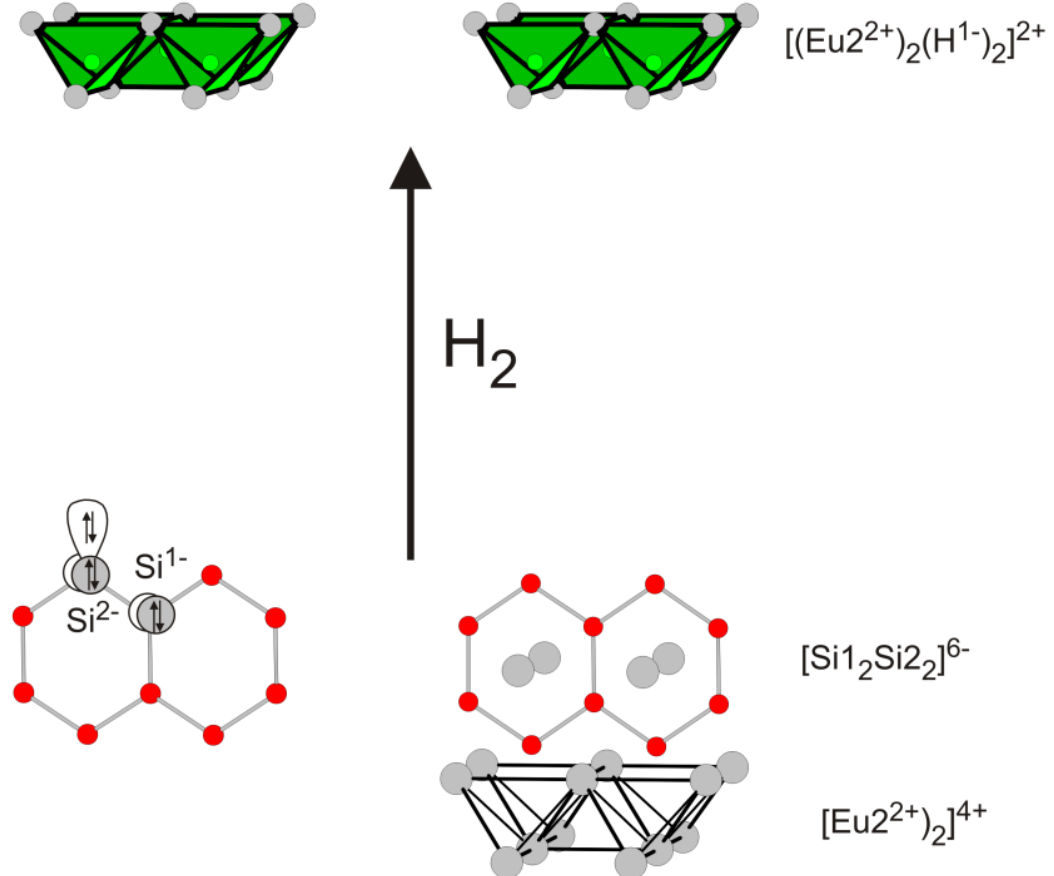

$\left[\mathrm{Si}_{2} \mathrm{Si2}_{2}\right]^{6-}$

$\mathrm{Eu}_{3} \mathrm{Si}_{4}$

$\left.\left[\mathrm{Eu}^{2+}\right)_{2}\right]^{4+}$ 
Figure 8.

a)

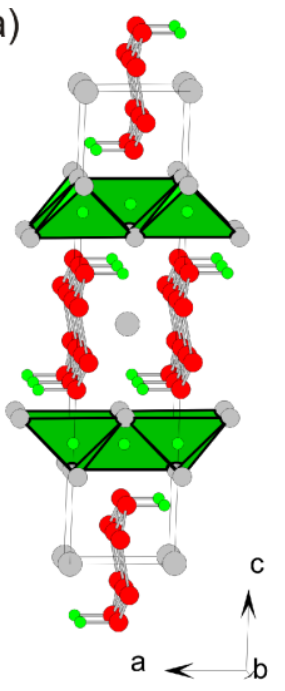

b)

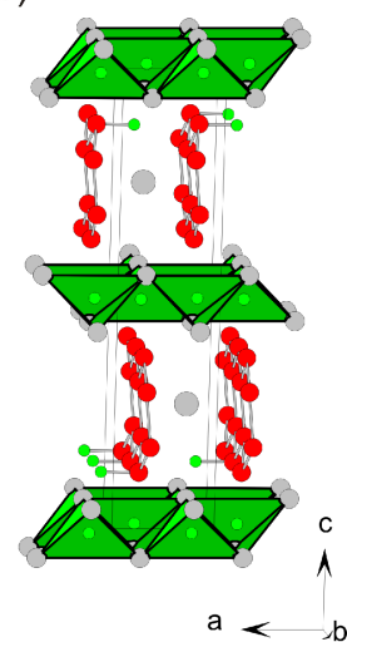


Figure 9.
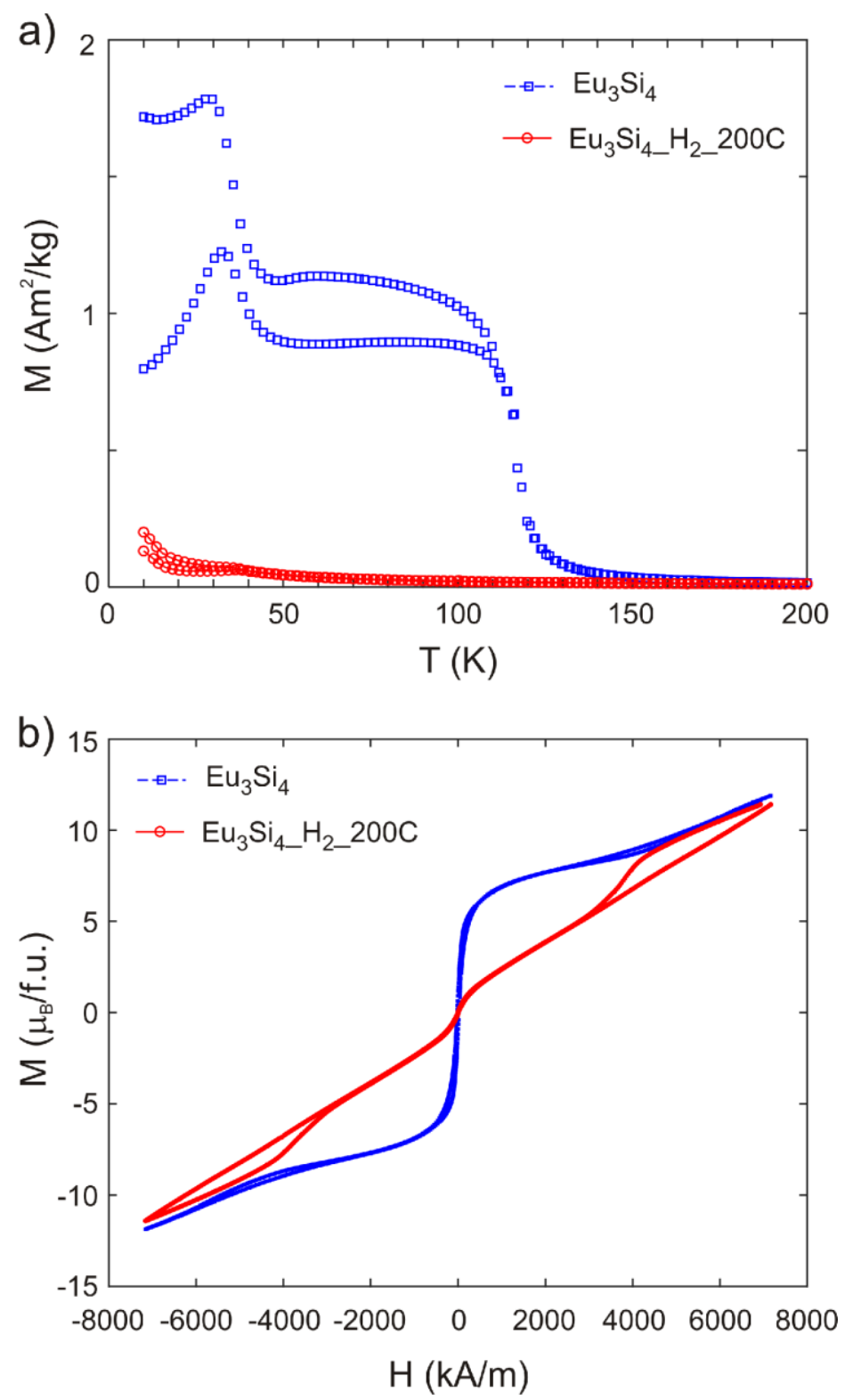


\section{Tables:}

Table 1: Crystallographic information for $\mathrm{Eu}_{3} \mathrm{Si}_{4}$ and hydrogenated $\mathrm{Eu}_{3} \mathrm{Si}_{4}$ samples from Rietveld refinements.

\begin{tabular}{|c|c|c|c|c|c|c|c|}
\hline SG: Immm & $a(\AA)$ & $b(\AA)$ & $c(\AA)$ & $V\left(\AA^{3}\right)$ & $\mathrm{R}_{\text {bragg }}$ & $R_{f}$ & $\chi^{2}$ \\
\hline $\begin{array}{c}\mathrm{Eu}_{3} \mathrm{Si}_{4} \\
\text { (ref. [13]) }\end{array}$ & $4.6164(4)$ & $3.9583(3)$ & $18.229(1)$ & $333.10(7)$ & & & \\
\hline $\mathrm{Eu}_{3} \mathrm{Si}_{4}$ & $4.61499(9)$ & $3.95949(8)$ & $18.2361(5)$ & $333.23(1)$ & 4.49 & 3.71 & 0.410 \\
\hline $\mathrm{Eu}_{3} \mathrm{Si}_{4} \_\mathrm{H}_{2} \_200 \mathrm{C}$ & $4.40055(5)$ & $3.97166(5)$ & $19.8098(3)$ & $346.225(8)$ & 4.8 & 3.68 & 0.831 \\
\hline $\begin{array}{l}\mathrm{Eu}_{3} \mathrm{Si}_{4} \_\mathrm{H}_{2} \_300 \mathrm{C} \\
\mathrm{Eu}_{3} \mathrm{Si}_{4} \mathrm{H}_{2+\mathrm{x}} \\
64(1) \% \\
\mathrm{Eu}_{3} \mathrm{Si}_{4} \mathrm{H}_{\sim 2} \\
35(7) \%\end{array}$ & $\begin{array}{r}4.40247(7) \\
4.4391(1)\end{array}$ & $\begin{array}{l}3.97478(9) \\
3.9778(1)\end{array}$ & $\begin{array}{l}19.8646(5) \\
19.5784(8)\end{array}$ & $\begin{array}{l}347.61(1) \\
345.72(2)\end{array}$ & $\begin{array}{l}5.35 \\
7.22\end{array}$ & $\begin{array}{l}4.06 \\
6.01\end{array}$ & 0.941 \\
\hline
\end{tabular}


Table 2: Atomic coordinates and isotropic displacement parameters for $\mathrm{Eu}_{3} \mathrm{Si}_{4}$ and hydrogenated $\mathrm{Eu}_{3} \mathrm{Si}_{4}$ samples.

\begin{tabular}{|c|c|c|c|c|c|c|}
\hline & Atom & Wyck & $x$ & $y$ & $z$ & $\mathrm{~B}\left(\AA^{2}\right)$ \\
\hline $\begin{array}{c}\mathrm{Eu}_{3} \mathrm{Si}_{4} \\
\text { (ref. [13]) }\end{array}$ & $\begin{array}{l}\text { Eu1 } \\
\text { Eu2 } \\
\text { Si1 } \\
\text { Si2 }\end{array}$ & $\begin{array}{l}2 a \\
4 j \\
4 i \\
4 j\end{array}$ & $\begin{array}{c}0 \\
1 / 2 \\
0 \\
1 / 2\end{array}$ & $\begin{array}{l}0 \\
0 \\
0 \\
0\end{array}$ & $\begin{array}{c}0 \\
0.31500(6) \\
0.4360(4) \\
0.1377(3)\end{array}$ & $\begin{array}{c}0.51(3) \\
0.54(2) \\
0.6(1) \\
0.7(1)\end{array}$ \\
\hline $\mathrm{Eu}_{3} \mathrm{Si}_{4}$ & $\begin{array}{l}\mathrm{Eu} 1 \\
\mathrm{Eu} 2 \\
\mathrm{Si} 1 \\
\mathrm{Si} 2\end{array}$ & $\begin{array}{l}2 a \\
4 j \\
4 i \\
4 j\end{array}$ & $\begin{array}{c}0 \\
1 / 2 \\
0 \\
1 / 2\end{array}$ & $\begin{array}{l}0 \\
0 \\
0 \\
0\end{array}$ & $\begin{array}{c}0 \\
0.31487(0) \\
0.43667(4) \\
0.13800(4)\end{array}$ & $\begin{array}{l}1.03(2) \\
1.03(2) \\
1.69(7) \\
1.69(7)\end{array}$ \\
\hline $\mathrm{Eu}_{3} \mathrm{Si}_{4} \_\mathrm{H}_{2} \_200 \mathrm{C}$ & $\begin{array}{l}\mathrm{Eu} 1 \\
\mathrm{Eu} 2 \\
\mathrm{Si} 1 \\
\mathrm{Si} 2\end{array}$ & $\begin{array}{l}2 a \\
4 j \\
4 i \\
4 j\end{array}$ & $\begin{array}{c}0 \\
1 / 2 \\
0 \\
1 / 2\end{array}$ & $\begin{array}{l}0 \\
0 \\
0 \\
0\end{array}$ & $\begin{array}{c}0 \\
0.31019(0) \\
0.440164) \\
0.12066(4)\end{array}$ & $\begin{array}{c}0.909(5) \\
0.909(5) \\
1.03(1) \\
1.03(1)\end{array}$ \\
\hline $\begin{array}{c}\mathrm{Eu}_{3} \mathrm{Si}_{4}{ }_{\mathrm{H}_{2}}{ }_{3} 300 \mathrm{C} \\
\mathrm{Eu}_{3} \mathrm{Si}_{4} \mathrm{H}_{2+\mathrm{x}}\end{array}$ & $\begin{array}{l}\text { Eu1 } \\
\text { Eu2 } \\
\text { Si1 } \\
\text { Si2 }\end{array}$ & $\begin{array}{l}2 a \\
4 j \\
4 i \\
4 j\end{array}$ & $\begin{array}{c}0 \\
1 / 2 \\
0 \\
1 / 2\end{array}$ & $\begin{array}{l}0 \\
0 \\
0 \\
0\end{array}$ & $\begin{array}{c}0 \\
0.31014(0) \\
0.44593(1) \\
0.12907(1)\end{array}$ & $\begin{array}{c}0.601(7) \\
0.601(7) \\
0.23(2) \\
0.23(2)\end{array}$ \\
\hline $\begin{array}{c}\mathrm{Eu}_{3} \mathrm{Si}_{4} \_\mathrm{H}_{2} \_300 \mathrm{C} \\
\mathrm{Eu}_{3} \mathrm{Si}_{4} \mathrm{H}_{\sim 2}\end{array}$ & $\begin{array}{l}\mathrm{Eu} 1 \\
\mathrm{Eu} 2 \\
\mathrm{Si} 1 \\
\mathrm{Si} 2\end{array}$ & $\begin{array}{l}2 a \\
4 j \\
4 i \\
4 j\end{array}$ & $\begin{array}{c}0 \\
1 / 2 \\
0 \\
1 / 2\end{array}$ & $\begin{array}{l}0 \\
0 \\
0 \\
0\end{array}$ & $\begin{array}{c}0 \\
0.31190(0) \\
0.43072(2) \\
0.11365(2)\end{array}$ & $\begin{array}{l}1.9(2) \\
1.9(2) \\
1.4(4) \\
1.4(4)\end{array}$ \\
\hline
\end{tabular}


Table 3: Cell parameters obtained by sequential Rietveld refinements of in-situ data.

\begin{tabular}{|l|l|l|l|l|l|}
\hline & Time $(\mathrm{h})$ & $a(\AA)$ & $b(\AA)$ & $c(\AA)$ & $V\left(\AA^{3}\right)$ \\
\hline Eu $_{3} \mathrm{Si}_{4}(93.9 \%)$ & & $4.6146(4)$ & $3.9572(3)$ & $18.229(2)$ & 332.90 \\
\hline Start & 0 & $4.6193(1)$ & $3.96156(9)$ & $18.2454(5)$ & 333.88 \\
\hline $250{ }^{\circ} \mathrm{C}$ & 0.78 & $4.4371(3)$ & $3.9836(2)$ & $19.785(1)$ & 349.73 \\
\hline $400{ }^{\circ} \mathrm{C}$ & 1.33 & $4.5085(2)$ & $3.9968(2)$ & $19.3128(8)$ & 348.02 \\
\hline $250{ }^{\circ} \mathrm{C}$ & 1.87 & $4.4397(2)$ & $3.9842(2)$ & $19.759(1)$ & 349.53 \\
\hline End & 2.63 & $4.4013(2)$ & $3.9756(2)$ & $19.857(1)$ & 347.47 \\
\hline
\end{tabular}

Table 4: Parameters of DFT optimized structures.

\begin{tabular}{|c|c|c|c|c|c|c|c|}
\hline & Atom & Wyck & $x$ & $y$ & $z$ & $a, b, c(\AA)$ & $V\left(\AA^{3}\right)$ \\
\hline \multirow{4}{*}{$\begin{array}{c}\mathrm{Eu}_{3} \mathrm{Si}_{4} \\
\operatorname{Immm}(71)\end{array}$} & Eu1 & $2 a$ & 0 & 0 & 0 & 4.5817 & \multirow{4}{*}{329.25} \\
\hline & Eu2 & $4 j$ & $1 / 2$ & 0 & 0.3156 & 3.9445 & \\
\hline & Sil & $4 i$ & 0 & 0 & 0.4351 & 18.2180 & \\
\hline & $\mathrm{Si} 2$ & $4 j$ & $1 / 2$ & 0 & 0.1383 & & \\
\hline \multirow{5}{*}{$\begin{array}{c}\mathrm{Eu}_{3} \mathrm{Si}_{4} \mathrm{H}_{2} \\
\operatorname{Immm}(71)\end{array}$} & Eu1 & $2 a$ & 0 & 0 & 0 & 4.4208 & \multirow{5}{*}{340.27} \\
\hline & Eu2 & $4 j$ & $1 / 2$ & 0 & 0.3064 & 3.9716 & \\
\hline & Si1 & $4 i$ & 0 & 0 & 0.4399 & 19.3803 & \\
\hline & $\mathrm{Si} 2$ & $4 j$ & $1 / 2$ & 0 & 0.1259 & & \\
\hline & H1 & $4 i$ & 0 & 0 & 0.2567 & & \\
\hline \multirow{10}{*}{$\begin{array}{c}\mathrm{Eu}_{3} \mathrm{Si}_{4} \mathrm{H}_{3} \\
P 2_{1} / m(11)\end{array}$} & Eu1 & $2 e$ & 0.2396 & $1 / 4$ & 0.2529 & 4.3903 & \multirow{10}{*}{342.56} \\
\hline & $\mathrm{Eu} 21$ & $2 e$ & 0.7364 & $1 / 4$ & -0.0585 & 3.9794 & \\
\hline & $\mathrm{Eu} 22$ & $2 e$ & 0.7483 & $1 / 4$ & 0.5560 & 19.6102 & \\
\hline & Si11 & $2 e$ & 0.2918 & $1 / 4$ & 0.8069 & $\beta=90.9^{\circ}$ & \\
\hline & Si12 & $2 e$ & 0.2444 & $1 / 4$ & 0.6876 & & \\
\hline & $\mathrm{Si} 21$ & $2 e$ & 0.7690 & $1 / 4$ & 0.1273 & & \\
\hline & $\mathrm{Si} 22$ & $2 e$ & 0.7492 & $1 / 4$ & 0.3768 & & \\
\hline & H11 & $2 e$ & 0.2414 & $1 / 4$ & -0.0045 & & \\
\hline & H12 & $2 e$ & 0.2458 & $1 / 4$ & 0.5068 & & \\
\hline & $\mathrm{H} 2$ & $2 e$ & 0.1366 & $1 / 4$ & 0.1286 & & \\
\hline $\mathrm{Eu}_{3} \mathrm{Si}_{4} \mathrm{H}_{4}$ & Eu1 & $2 a$ & 0 & 0 & 0 & 4.4192 & \multirow{6}{*}{348.10} \\
\hline \multirow[t]{5}{*}{$I 2 / m(12)$} & $\mathrm{Eu} 2$ & $4 i$ & 0.4836 & 0 & 0.6916 & 3.9625 & \\
\hline & Sil & $4 i$ & 0.0551 & 0 & 0.5593 & 19.8895 & \\
\hline & $\mathrm{Si} 2$ & $4 i$ & 0.5204 & 0 & 0.8765 & $\beta=91.9^{\circ}$ & \\
\hline & $\mathrm{H} 1$ & $4 i$ & -0.0070 & 0 & 0.7450 & & \\
\hline & $\mathrm{H} 2$ & $4 i$ & 0.1162 & 0 & 0.1231 & & \\
\hline
\end{tabular}

